\title{
Can the Dynamic Colouration and Patterning of Bluelined Goatfish (Mullidae; Upeneichthys lineatus) Be Perceived by Conspecifics?
}

\author{
Louise Tosetto $^{a}$ Jane E. Williamson ${ }^{a, b}$ Thomas E. White ${ }^{c}$ Nathan S. Hart ${ }^{a}$ \\ a Department of Biological Sciences, Macquarie University, Sydney, NSW, Australia; b Sydney Institute of Marine \\ Science, Mosman, NSW, Australia; 'School of Life and Environmental Sciences, The University of Sydney, Sydney, \\ NSW, Australia
}

\section{Keywords}

Visual ecology $\cdot$ Teleost fishes $\cdot$ Spectral sensitivity $\cdot$ Colour change $\cdot$ Visual acuity

\begin{abstract}
Bluelined goatfish (Upeneichthys lineatus) exhibit dynamic body colour changes and transform rapidly from a pale, buff/ white, horizontally banded pattern to a conspicuous, vertically striped, red pattern when foraging. This red pattern is potentially an important foraging signal for communication with conspecifics, provided that $U$. lineatus can detect and discriminate the pattern. Using both physiological and behavioural experiments, we first examined whether $U$. lineatus possess visual pigments with sensitivity to long ("red") wavelengths of light, and whether they can discriminate the colour red. Microspectrophotometric measurements of retinal photoreceptors showed that while $U$. lineatus lack visual pigments dedicated to the red part of the spectrum, their pigments likely confer some sensitivity in this spectral band. Behavioural colour discrimination experiments suggested that $U$. lineatus can distinguish a red reward stimulus from a grey distractor stimulus of variable brightness. Furthermore, when presented with red stimuli of varying brightness they could mostly discriminate the darker and lighter reds from the grey distractor. We also obtained anatomical estimates
\end{abstract}

karger@karger.com www.karger.com/bbe

Karger $\stackrel{\text { ' }}{5}$
(C) 2021 The Author(s)

Published by S. Karger AG, Basel

This is an Open Access article licensed under the Creative Common Attribution-NonCommercial-4.0 International License (CC BY-NC) (http://www.karger.com/Services/OpenAccessLicense), applicable to the online version of the article only. Usage and distribution for commercial purposes requires written permission. of visual acuity, which suggest that $U$. lineatus can resolve the contrasting bands of conspecifics approximately $7 \mathrm{~m}$ away in clear waters. Finally, we measured the spectral reflectance of the red and white colouration on the goatfish body. Visual models suggest that $U$. lineatus can discriminate both chromatic and achromatic differences in body colouration where longer wavelength light is available. This study demonstrates that $U$. lineatus have the capacity for colour vision and can likely discriminate colours in the long-wavelength region of the spectrum where the red body pattern reflects light strongly. The ability to see red may therefore provide an advantage in recognising visual signals from conspecifics. This research furthers our understanding of how visual signals have co-evolved with visual abilities, and the role of visual communication in the marine environment.

(c) 2021 The Author(s)

Published by S. Karger AG, Basel

\section{Introduction}

Many fishes exhibit changes in integumentary colour and pattern. These can take place gradually throughout development and with shifts in habitat but can also happen very rapidly in relation to specific behaviours [Mäthger et al., 2003; Nilsson Sköld et al., 2013; Rodgers et al., 


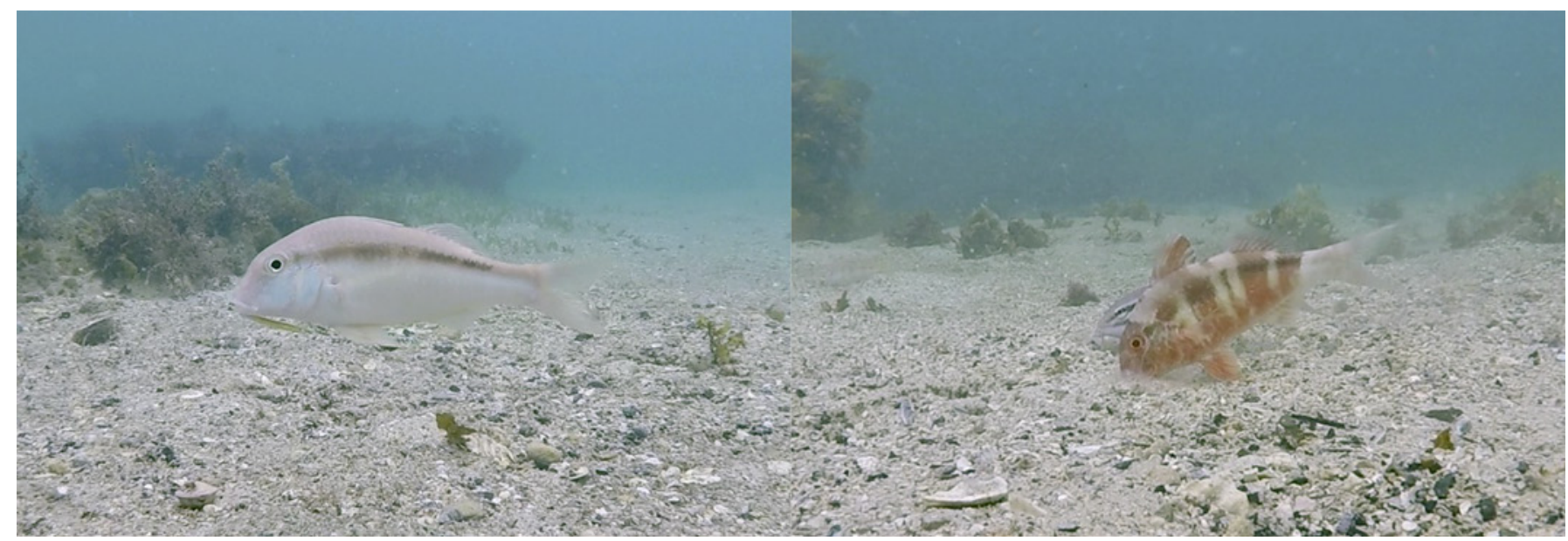

Fig. 1. Different colour forms exhibited by the bluelined goatfish (Upeneichthys lineatus). These images are the same individual $(\sim 23 \mathrm{~cm})$ photographed $20 \mathrm{~s}$ apart. The image on the left shows the plain colouration of the bluelined goatfish, the image on the right is the red-banded colour that is often observed when the goatfish forage.

2013]. Rapid colour change may be important for camouflage or used as visual communication within or between species [Stuart-Fox and Moussalli, 2008]. One family of fish known to alter their colouration rapidly are the goatfish (Mullidae) [Hunter, 1967; Uiblein, 2011] and in many species, the behavioural drivers of this colour change have not been established. The bluelined goatfish (Upeneichthys lineatus, Bloch and Schneider, 1801), found along the south-east coast of Australia, has highly dynamic body colouration and can change from mostly white to a vertical red-banded pattern in seconds. This can take place at night when the fish is resting, but during the day they regularly transform their body pattern when foraging, seemingly making them more conspicuous (Fig. 1). Goatfish, including U. lineatus, are routinely followed by conspecifics and other species of fishes [Sazima et al., 2006; Uiblein, 2007] and it is thought that their foraging activity, which disturbs the substrate, increases prey availability for other species [Lukoschek and McCormick, 2002]. The red patterning exhibited by $U$. lineatus may act as a foraging signal to conspecifics to collaborate for increased food acquisition or predator awareness - a safety in numbers approach [Hager and Helfman, 1991]. To establish whether rapid colour change is being used as a signal, however, it is essential to understand if potential receivers of the signal can perceive it, in this case, whether conspecifics can distinguish changes in colour and pattern from white to red and white vertical bands.
Object detection and discrimination rely on several different properties of the visual system that vary widely between animals, including fishes. Spatial resolving power, or visual acuity, is the ability to distinguish between adjacent parts of the retinal image that differ in brightness. Visual acuity depends primarily on receptor size and spacing, and the degree of neural summation (signal pooling) in the retina. Adaptations to increase visual acuity (e.g., narrower photoreceptors) often come at the expense of absolute sensitivity, which means that visual acuity is strongly influenced by the ambient light environment. Nocturnal animals or those living in dim habitats generally possess poor visual acuity compared to diurnal species and those living in brighter habitats. Differences in visual acuity are also correlated with habitat complexity, foraging strategies and other lifestyle characteristics [Collin and Pettigrew, 1989; Parker et al., 2017].

To perceive objects, animals must also possess visual pigments with sensitivity to the wavelengths of light that they reflect and have the appropriate light spectrum available [Endler, 1990; Siebeck et al., 2008; Marshall et al., 2015]. The photic environment that animals inhabit is considered to have the biggest influence on the photoreceptor complement and spectral sensitivities of an animal, especially in aquatic habitats [Schweikert et al., 2018]. For instance, nocturnally active animals or those inhabiting deep-water environments often relinquish colour vision and many have rod-only retinas that are specialised for scotopic, or low light, vision [Kelber et al., 
2003; Warrant and Locket, 2004; Marshall et al., 2015]. In contrast, fish inhabiting well-lit, shallower marine environments, such as tropical coral reefs, are exposed to bright light and typically have multiple spectral cone types that provide the potential for colour vision [Siebeck and Marshall, 2001]. In coastal areas, such as where $U$. lineatus are found, suspended and dissolved organic material absorbs and scatters shorter and longer wavelengths of light [Bowmaker et al., 1993]. This results in a rapid reduction of overall light intensity and a shift in the dominant wavelengths of light towards the blue-green waveband of the spectrum [Bowmaker, 1984; Lythgoe and Partridge, 1991]. Fish inhabiting these areas tend to have visual pigments with wavelengths of peak absorption $\left(\lambda_{\max }\right)$ that coincide with the spectral envelope that encompasses the dominant wavelengths (440-550 nm) and typically lack longwave-sensitive (red) cone pigments [Bowmaker, 1990; Marshall et al., 2015].

Colour vision is the ability of an organism to distinguish objects based on their spectral composition (hue) independently of their brightness [Kelber et al., 2003]. A key requirement for colour vision is the possession of at least two types of cone photoreceptors containing visual pigments with peak sensitivity in different spectral regions [Osorio and Vorobyev, 2005]. Visual pigments are photoreceptive molecules, consisting of a light-absorbing chromophore bound by an opsin protein [Wald, 1968]. The spectral sensitivity of the pigments can be tuned by the modification of the opsin protein amino acids [Carleton and Kocher, 2001]. Animals that have a single spectral class of photoreceptor can only extract information about an object's brightness from the retinal image [Bowmaker, 1995]. In addition to photoreceptors with different spectral sensitivities, colour vision also requires opponent neural circuits that can compare the outputs of these different photoreceptor types and encode the chromatic signal [Kelber, 2016].

To establish whether an animal has spectrally distinct cone photoreceptors, the absorbance spectra of the visual pigments expressed in the retina can be measured using microspectrophotometry [Bowmaker, 1984; Hart, 2002]. To date, microspectrophotometric measurements of visual pigment spectral absorbance have been conducted on over 200 species of fish [Schweikert et al., 2018]. Of the goatfishes, microspectrophotometric data are available for four species, including the bartail goatfish (Upeneus tragula) [Shand, 1993]. U. tragula occurs predominately in tropical Indo-Pacific waters, but also occasionally occupies similar habitats to $U$. lineatus [Tosetto, unpubl. data]. During their pelagic phase in surface waters, U. tra- gula larvae possess single cones maximally sensitive to short wavelengths (SWS; $\lambda_{\max } \leq 400 \mathrm{~nm}$ ) and paired/double cones maximally sensitive in the medium- (MWS; $\lambda_{\max } 487 \mathrm{~nm}$ ) and long- (LWS; $\lambda_{\max } 580 \mathrm{~nm}$ ) wavelength parts of the spectrum, in addition to an MWS $\operatorname{rod}\left(\lambda_{\max }\right.$ $499 \mathrm{~nm}$ ). The LWS pigment is lost, however, in U. tragula after settlement, potentially due to changes in the ambient light environment when transitioning from a pelagic to benthic lifestyle, with wavelengths above $530 \mathrm{~nm}$ almost entirely absent below 10 m [Shand, 1993]. Given the similarities in habitat and life history between $U$. tragula and $U$. lineatus, it is possible that adult $U$. lineatus also lack LWS visual pigments, raising the question of whether they can discriminate reflectance spectra, such as their own red body colouration, in this spectral waveband. In this study, we measured the visual pigments of $U$. lineatus using microspectrophotometry and show that they have three spectrally distinct visual pigments.

While microspectrophotometry can reveal photoreceptor spectral sensitivities, it cannot provide information on chromatic processing in the retina or brain. Moreover, given the apparent variability in the expression of visual opsins depending on environmental and/or ontogenetic shifts [Hofmann and Carleton, 2009], microspectrophotometry only provides a snapshot in time and space of the colour that an animal has the capacity to see [Marshall, 2017]. Hence, while microspectrophotometry is an important tool in demonstrating a neural basis for colour discrimination, ultimately it is the behaviour of the animal relative to a particular colour that allows us to understand whether it has the capacity to perceive this colour [Marshall et al., 2015]. Behavioural experiments assessing colour vision have been conducted with several fish species [Neumeyer, 1986; Siebeck et al., 2008; Pignatelli et al., 2010; Escobar-Camacho et al., 2017] and are generally done via operant conditioning. We used a similar approach in this study to determine whether U. lineatus have colour vision and show that they are capable of discriminating ecologically relevant spectra. Given longer wavelengths of light are not always available, we also assessed how well $U$. lineatus can discriminate the banded pattern. Thus, we obtained anatomical estimates of acuity and modelled the spatial information resolvable by $U$. lineatus at a range of distances. Finally, we measured the spectral reflectance of the white and red colouration of different $U$. lineatus individuals and modelled the colour distances at different depths to gain insight into whether conspecifics may discriminate colour change using chromatic or achromatic differences. 


\section{Materials and Methods}

\section{Animal Capture and Housing}

All procedures were approved by the Macquarie University Animal Ethics Committee (ARA 2016/020). Animals were collected under permits granted by NSW Department of Primary Industries (P08/0010-4.2).

Fish were collected at 2-4 m depth between July 2017 and December 2018 from Camp Cove, Sydney, Australia (3350'21" S, $\left.151^{\circ} 16^{\prime} 45^{\prime \prime} \mathrm{E}\right)$. Fish were captured on SCUBA using hand nets and a small fine-mesh seine net $(122 \times 244 \mathrm{~cm})$ with a mesh size of 3.2 $\mathrm{mm}$. Once captured, fish were transported in aerated seawater to the Macquarie University Seawater Facility. This facility comprises 45,000 litres of recirculated seawater, which is collected from depth in Sydney Harbour. Goatfish were housed individually in light grey PVC aquaria $(600 \times 350 \mathrm{~mm})$ and maintained at a flow rate of $1 \mathrm{~L} \mathrm{~min}{ }^{-1}$, a temperature of $17-23^{\circ} \mathrm{C}$ and a salinity of 35 ppt. Sieved beach sand ( $20 \mathrm{~mm}$ depth) collected from the fish's habitat was used as substrate. Aquaria were illuminated with two full-spectrum LED lights $(120 \mathrm{~cm}$ DEE Full Spectrum Marine Aquarium LED Light), with an equal amount of light illuminating all aquaria, and were illuminated on a 12-h light:12-h dark regime. A large white PVC pipe (300 $\mathrm{mm}$ long, $100 \mathrm{~mm}$ diameter) was placed into each tank to serve as a shelter for the fish. Aquaria were cleaned and fish were fed twice daily with a mixture of frozen brine shrimp, blood worm and mysis shrimp (Aquarium Industries Naturals Frozen Food, Australia). Each fish was given approximately $40-50 \mathrm{ml}$ of frozen food per day. Diets were supplemented daily with two fresh pippies (Donax donax) per fish when not in their trials.

\section{Microspectrophotometry}

Six right eyes from 6 individuals (total length $13-19 \mathrm{~cm}$ ) were used for microspectrophotometry. Fish were dark adapted for $2 \mathrm{~h}$ prior to euthanasia with an overdose of the fish anaesthetic tricaine methanesulphonate salt (MS222, Sigma; 1:2,000). Eyes were removed under dim red light, dissected under a bank of 24 infrared light emitting diodes and visualised using an infrared image converter (Electroviewer 7215, Electrophysics) attached to one ocular of a stereo dissecting microscope. Following removal, each eye was hemisected at the equator, and the posterior eye cup containing the retina was placed in phosphate-buffered saline (PBS; $420 \mathrm{mosm}^{-1}$; $\mathrm{pH}$ 7.2). Small pieces of retinal tissue $\left(1-2 \mathrm{~mm}^{2}\right)$ were dissected away from the eye cup and transferred to the middle of a $24 \times 60$ mm No. 1 glass coverslip containing a drop of PBS with $10 \%$ dextran (MW 282,000; Sigma D-7265). The piece of retina was gently teased apart using fine point tweezers and covered with a $22 \times 22$ $\mathrm{mm}$ No. 0 glass coverslip. Gentle pressure was applied to the top of the coverslip to remove excess PBS from the slide. The edges of the top coverslip were sealed with clear nail varnish to prevent dehydration.

Spectral absorbance measurements (330-800 nm) were made of cone and rod outer segments using a computer controlled, single-beam wavelength scanning microspectrophotometer [Hart, 2004]. A sample scan was first made by aligning the measuring beam (normally measuring $1 \times 3 \mu \mathrm{m}$ ) within a single outer segment of a cone or rod photoreceptor and recording the amount of light transmitted at each wavelength. A baseline scan was then made using the same approach after moving the measuring beam to an adjacent area without any tissue. Baseline transmittance was sub- tracted from the sample at each equivalent wavelength, creating a "prebleach" spectrum. Outer segments were subsequently bleached with full spectrum "white" light from the monochromator for 2 min before new sample and baseline scans were made to create a "postbleach" spectrum. The dimensions of photoreceptor outer segments were measured from an image of the retina projected to a CCTV screen used to view the preparation [Hart, 2004].

\section{Spectral Analysis}

Baseline and sample data were converted to absorbance values at $1-n m$ intervals. Spectra were then smoothed with a variablepoint unweighted running average and normalised to maximum and minimum absorbances. The minimum absorbance was obtained by averaging the absorbance values between 630 and 780 $\mathrm{nm}$. A least-squares regression line was fitted to the normalised absorbance data between 70 and $30 \%$ of the maximum absorbance on the long-wavelength limb of the spectrum. The regression equation was used to predict the wavelength of maximum sensitivity $\left(\lambda_{\max }\right)$ following the methods of MacNichol [1986] and modified by Govardovskii et al. [2000]. A pure rhodopsin $\left(\mathrm{A}_{1}\right)$ or porphyropsin $\left(A_{2}\right)$ absorbance template [Govardovskii et al., 2000] with an appropriate $\lambda_{\max }$ was overlain on the absorbance data. Scans from each photoreceptor type that satisfied established selection criteria [Levine and MacNichol Jr., 1985; Partridge et al., 1992] were accepted and saved for further analysis.

\section{Spectral Transmission of the Preretinal Ocular Media}

The cornea and lens were removed from the eye, and their spectral transmittance $(300-700 \mathrm{~nm})$ was measured using an Ocean Optics USB4000 spectrophotometer. Light from a 150-W xenon arc lamp was delivered to the sample via a $600-\mu \mathrm{m}$ diameter quartz fibre-optic cable fitted with a quartz collimating lens (Ocean Optics). Light that passed through the ocular media was collected with a $100-\mu \mathrm{m}$ diameter quartz fibre-optic cable fitted with a quartz collimating lens (Ocean Optics). All samples were measured in air [Douglas and McGuigan, 1989]. The cornea was orientated so that the front of the cornea was facing the light source. For each animal, three measurements of each cornea and lens were taken. Curves were normalised so that the transmittance at $700 \mathrm{~nm}$ equalled 1 (Fig. 2c).

\section{Anatomical Measurements of Visual Acuity}

Animals were euthanised with an overdose $(1: 2,000)$ of MS222. Retinal whole-mount procedures were adapted from Ullmann et al. [2012]. Ganglion cell counts were performed on an Olympus BX63 compound microscope fitted with an electronic stage and an Olympus DP80 camera. Stage movement and the camera were controlled by cellSens Entry software (Olympus, version: 1.17, core version: X V 3.16, build 16030). The total numbers of neurons in the retinal ganglion cell (RGC) layer were counted using a $\times 100 / 1.40$ NA oil immersion objective. Counts were made at 0.5 mm intervals with a $100 \times 100 \mu \mathrm{m}$ counting frame, providing approximately 400 sample locations across the retina. Given the difficulty in differentiating between ganglion and amacrine cells in the areas of high density, all neural cells were counted together (Fig. 3a).

The convergence of visual information between photoreceptors and ganglion cells, via interneurons, influences how an image is perceived through signal summation [Lythgoe, 1979; Warrant, 1999]. Low summation of neural signals between photoreceptors 


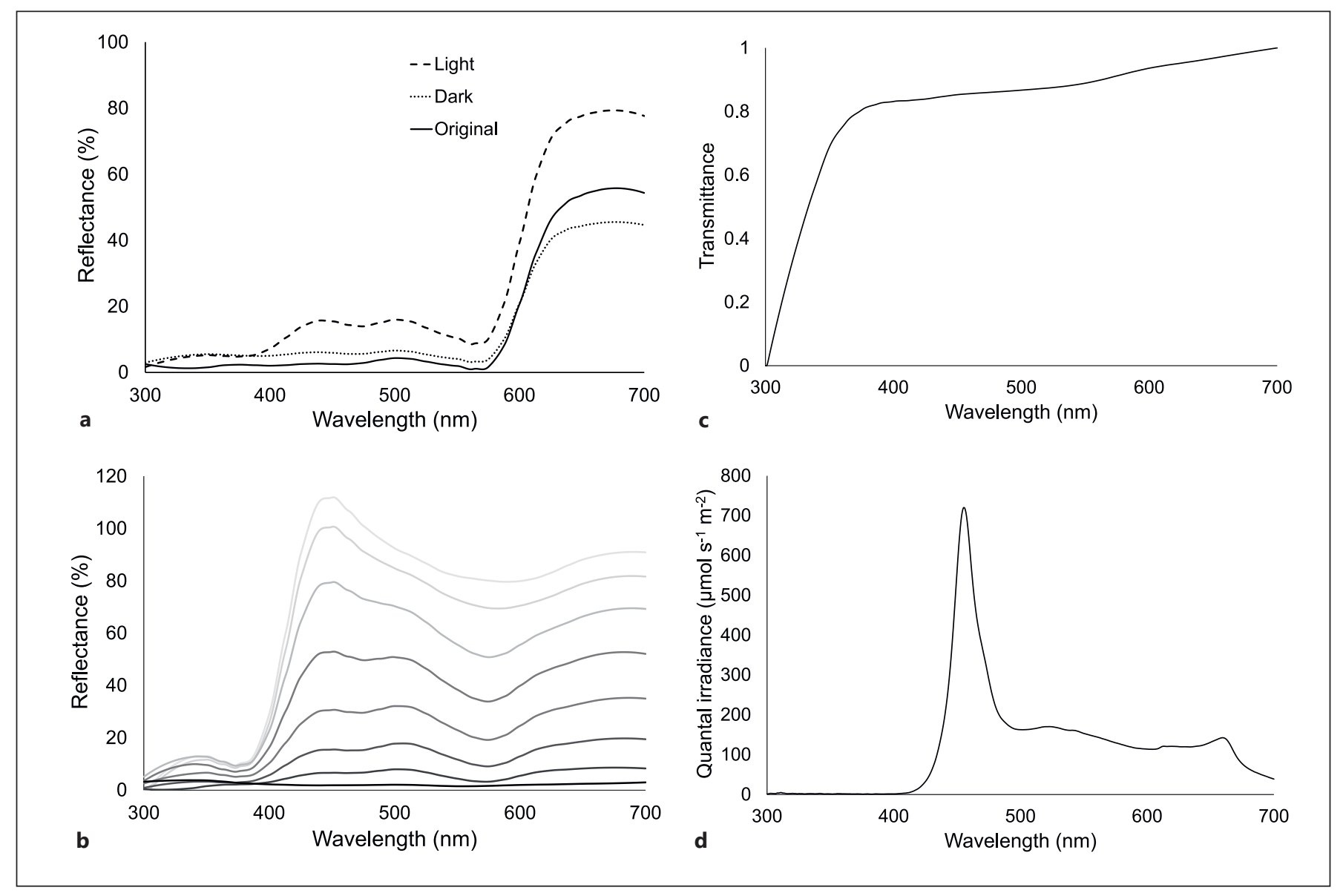

Fig. 2. a Spectral reflectance of the original red stimuli used in two- and three-card discrimination experiments, and the light and dark red stimuli used in the different brightness experiment. $\mathbf{b}$ Spectral reflectance of the 8 distractor grey stimuli used in all experiments. c Spectral transmittance of the ocular media. d Downwelling spectral irradiance of the experimental arena used for the behavioural tests.

and ganglion cells will generally result in higher visual acuity, at the expense of sensitivity [Litherland and Collin, 2008]. Outer segments of photoreceptors were examined and counted using the same slides prepared for examination of the ganglion cell layer. Using the same $x-y$ coordinates from the ganglion cells, we chose 15-20 grids in both the area centralis and periphery to obtain photoreceptor counts (Fig. 3b). Convergence was calculated as the number of photoreceptor cells divided by the number of ganglion cells within an area of $1 \mathrm{~mm}^{2}$.

To obtain topographic maps of neurons in the ganglion cell layer, the retina was reconstructed by mapping the retinal flat mounts into a standard, hemispherical retinal space using the $\mathrm{R}$ package "retistruct" [Sterratt et al., 2013]. The retina was traced using the composite retinal image obtained before counting using the polygon tool in ImageJ (v.1.53) [Schneider et al., 2012] and saved as a region of interest file. The falciform process/optic nerve was also traced and saved as an $x-y$ coordinate text file. The locations of cuts and tears in the retina and periphery as well as the orientation were marked up in retistruct, and the retina was reconstructed. The neuronal count data were then placed onto the re- constructed retina using the R package "retina" [Cohn et al., 2015] to generate the spherical coordinates, apply thin plate spline smoothing, and plot the isodensity contours.

Spatial Resolving Power and Pattern Detection Distance

The theoretical (anatomical) peak spatial resolving power was estimated for $U$. lineatus from the maximum density of RGCs in the retina and the focal length as outlined by Lisney and Collin [2008]. In this case, we assume that RGCs are the limiting factor for spatial resolving power, and that they are packed in a hexagonal array. We also calculated acuity based on maximum photoreceptor densities. Because $U$. lineatus were found to have a square photoreceptor mosaic across its retina (Fig. $3 \mathrm{~b}$ ), calculations of acuity were based on inter-cone spacing and followed the methods for square mosaics where the spatial resolution is calculated by obtaining the number of cells subtended by $1^{\circ}$ of visual arc [Collin and Pettigrew, 1989]. To estimate the furthest distance at which $U$. lineatus can resolve the vertical bands before they become blurred, we used calculations provided by Marshall [2000]. We used measurements from a previously sampled 22-cm (total length) adult $U$. 

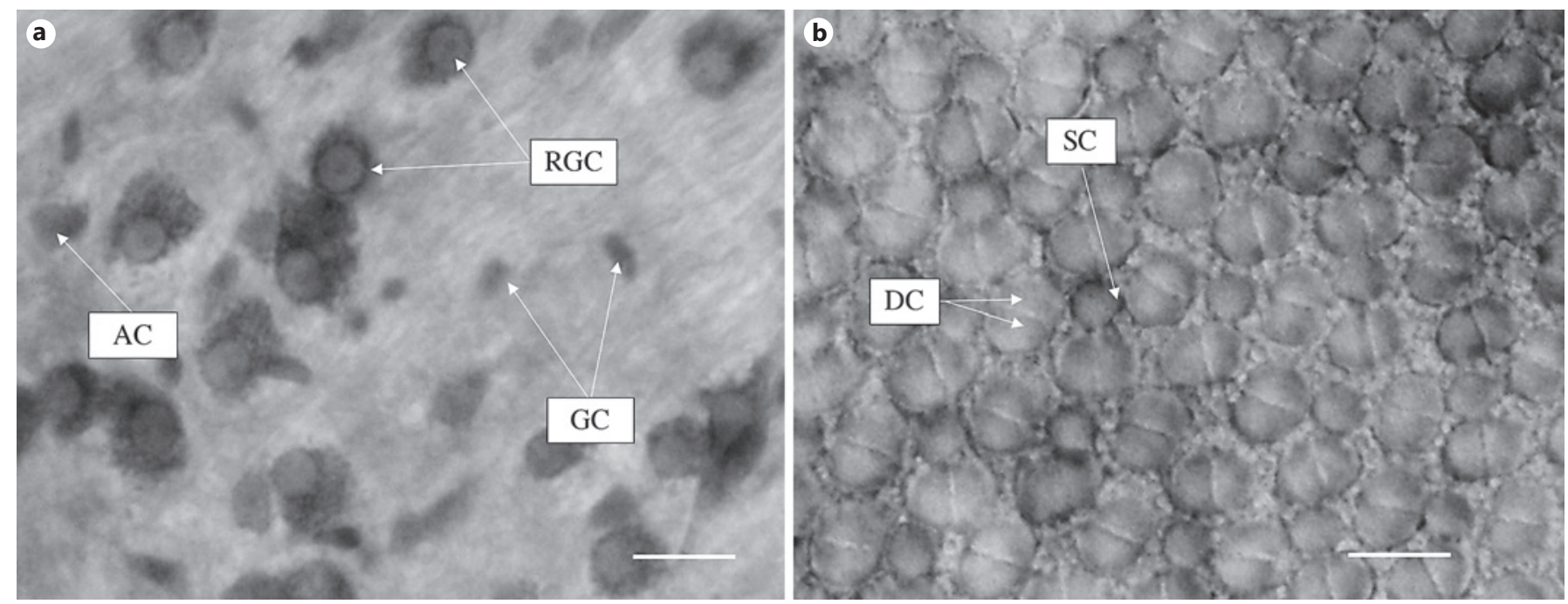

Fig. 3. Photomicrographs. a Retinal ganglion cell layer. $\times 100$. b Photoreceptor layer showing the square cone mosaic. $\times 100$. RGC, retinal ganglion cell; GC, glial cell; AC putative amacrine cell; DC double cone; SC, single cone. The scale bar is $10 \mu \mathrm{m}$ in length.

lineatus with vertical bands of approximately $1 \mathrm{~cm}$ wide, doubled to give a full "grating" cycle of $2 \mathrm{~cm}$ required for the calculations. To approximate the spatial information resolvable by conspecifics at a range of distances we used the R package "AcuityView" [Caves and Johnsen, 2018] to modify individual frames and estimate only the spatial information that is resolvable given knowledge of a viewer's acuity and the distance to the object being viewed. We modelled this for a conspecific $U$. lineatus and, by way of comparison, a blind shark (Brachaelurus waddi) and a human viewer.

\section{Behavioural Experiments}

Behavioural experiments to assess colour vision were completed via operant conditioning based on the classic grey card paradigm [Von Frisch, 1914]. The overall objective for the behavioural trials was for individuals to discriminate a red (as perceived by humans) coloured stimulus from a range $(n=8)$ of grey distractor stimuli of differing brightness, on the premise that the task can only be solved if the fish can distinguish the reward stimuli based on hue (red) alone because brightness is an unreliable cue [Siebeck et al., 2008; Dyer et al., 2015]. To assess whether goatfish use hue as a discriminating tool, individuals were also presented with different luminance levels of the rewarded colour (lighter red and darker red) and tested against the grey distractor stimuli.

\section{Visual Stimuli}

Three reward (red) stimuli (original, lighter, and darker) and the 8 grey distractor stimuli (all $6 \times 4 \mathrm{~cm}$ cards) were created in Adobe Illustrator (version 23.0.5, 2019). The cards were printed commercially on photographic paper (250 GSM A4 matte; Krisp, Hoppers Crossing, VIC, Australia) and laminated using transparent plastic pouches (gloss, Signature laminating pouches, $125 \mu \mathrm{m}$, $\left.\mathrm{A} 4 ; \mathrm{GBC}^{\circledR}, \mathrm{USA}\right)$. Multiple copies of each card were made and used randomly in experiments so that any other factors, such as differing brightness or printing inconsistencies, could be ruled out [Van-Eyk et al., 2011]. Reflectance spectra of the reward and dis- tractor laminated cards (Fig. 2a, b) were measured using an Ocean Optics USB4000-FL spectrometer and a PX-2 pulsed xenon light source, calibrated against a Spectralon (Labsphere, Congleton, UK) $99 \%$ white standard (further detailed below).

\section{Irradiance Measurements}

The spectral irradiance (Fig. 2d) of the experimental arena was measured using an OceanInsight JAZ EL-200 portable spectroradiometer fitted with a cosine-corrected irradiance module (OceanInsight, Dunedin, FL, USA). Absolute irradiance, $\mathrm{E}(\lambda)$ in $\mu$ watt $\mathrm{cm}^{-2} \mathrm{~nm}^{-1}$ was converted to the photon (quantum) flux $\mathrm{Q}(\lambda)$ in $\mu \mathrm{mol} \mathrm{s}{ }^{-1} \mathrm{~m}^{-2} \mathrm{~nm}^{-1}$ using the irrad2flux function in the R package "pavo" [Maia et al., 2019].

\section{Visual Modelling}

Spectral processing and visual modelling were carried out using the R package "pavo" [Maia et al., 2019]. First, stimulus reflectance spectra were trimmed to $300-700 \mathrm{~nm}$, and spurious negative reflectance values were set to zero using the procspec command. Using the vismodel function, we then estimated receptor quantum catches for each reward and distractor stimulus as the integrated product of stimulus reflectance, photoreceptor spectral sensitivity, the illuminating (irradiant) spectrum in the experimental arena, and receptor absorbances accounting for the transmittance of the goatfish ocular media, across the 300 - to $700-\mathrm{nm}$ waveband [Vorobyev et al., 1998; equation 1]. We wanted the model to assess whether $U$. lineatus could distinguish between visual stimuli based on the extremes of their spectral sensitivity. Thus, the photoreceptor spectral sensitivity $\left(S_{i}\right)$ data entered were the SWS single cone absorbance spectra (mean $\lambda_{\max }$ of $412 \mathrm{~nm}$ ) and 2 individual cones representing visual pigments from the shortest $\left(\lambda_{\max } 483 \mathrm{~nm}\right)$ and longest $\left(\lambda_{\max } 545 \mathrm{~nm}\right)$ parts of the spectrum covered by the double cones, rather than the averaged data for the double cones (see online suppl. material, Fig. S2; for all online suppl. material, see www. karger.com/10.1159/000519894 for the scans of these photorecep- 
tors). To calculate luminance (achromatic) receptor stimulation we used the summed response of the MWS and LWS photoreceptors. In the absence of specific values for $U$. lineatus, we specified a relative receptor density of 1:2:2 (short:medium:long) and a Weber fraction of 0.05 as per Champ et al. [2016]. To predict whether the reward and distractor stimuli, and the test board, could be distinguishable to goatfish, we used the coldist function to calculate noise-weighted chromatic $(\Delta \mathrm{S})$ and achromatic $(\Delta \mathrm{L})$ Euclidean distances based on the receptor-noise limited model [Vorobyev and Osorio, 1998].

Food and Feeding Apparatus

A feeding apparatus adapted from Siebeck et al. [2008] was developed to feed fish during training and behavioural trials. The apparatus consisted of a glass tube ( $7 \mathrm{~mm}$ diameter, $300 \mathrm{~mm}$ long) attached to a small piece of plastic tube ( $4 \mathrm{~mm}$ diameter, $100 \mathrm{~mm}$ long) and a 30 -mL syringe filled with the food mixture. This was effective in that it allowed delivery of small amounts of food, something that was necessary during training. Fish were fed a mixture of frozen brine shrimp, mysis shrimp and bloodworms (Ocean Nutrition) during training and behavioural trials, which was defrosted and mixed with seawater. This feeding apparatus also ensured prompt delivery of food without the presence of air bubbles. The syringe was accessible to the tester and food was delivered to the fish from underneath the centre of the test board (see experimental design below) once the fish had selected the correct card. Any side bias in food delivery was removed by delivering the feed from the middle of the test board rather than from underneath a particular stimulus.

\section{Experimental Design}

To minimise disruption, fish were trained and tested in their home aquaria (details provided above). During testing, an opaque grey acrylic $(35 \times 28 \mathrm{~cm})$ barrier (the start barrier) was placed halfway in the housing tank, so that the back of the tank containing the fish became a start arena and the front of the tank was blocked off. Once the fish was contained in the start arena, a test board with the visual stimuli attached was placed at the front of the tank. Upon commencement of the trial the start barrier was lifted, and the fish was presented with a reward and distractor stimuli on a grey Perspex test board $(35 \times 28 \mathrm{~cm})$. The fish was provided with a food reward from underneath the middle of the test board if it selected the "red" reward card. All trials were recorded with a GoPro ${ }^{\mathrm{TM}} \mathrm{Hero} 5$ camera and watched by the observer remotely on an Apple iPad ${ }^{\mathrm{TM}}$ using the GoPro App (version 5.2.4) (online suppl. Fig. S1, video S1 and S2).

\section{Training}

Individual fish were first trained to associate a red stimulus $(6 \times 4 \mathrm{~cm}$ card $)$ with a food reward. Once fish were acclimated into their tanks (approx. 1-2 weeks) the red stimulus was introduced into the tank. The card was placed at the end of the $300-\mathrm{mm}$ tube on the feeding apparatus. Initially the feeding apparatus and stimulus were placed in the tank and food was provided near the fish or near their shelter if they were hiding inside. This was repeated twice daily until the fish gradually moved towards the stimulus and eventually "tapped" the stimulus with its barbels to release the food reward. Once the fish tapped the stimulus reliably, defined as sustained contact for at least $2 \mathrm{~s}$, the start barrier was introduced to create the start box. Once the fish reliably and regularly tapped the red card on the test board and was familiar with the task and start barrier, testing of the red stimulus against the grey distractor stim- uli commenced in choice discrimination experiments. Three fish did not reliably tap the red card during the training process and were thus excluded from the discrimination experiments. Fish were not exposed to the grey brightness distractors until testing in the two-choice discrimination experiments had commenced.

\section{Two-Choice Discrimination Experiment: Fixed Reward Card} Brightness

The first experiment tested 9 fish individually with a twochoice discrimination task. In this task, fish were required to select a red stimulus (of a single fixed brightness, see above) as the reward when they viewed the stimulus adjacent to 1 of the 8 different grey distractor stimuli in a set of trials. In any given trial the red reward stimulus was viewed together with a grey distractor stimulus that was selected at random. For testing, fish were first isolated in the start box. The red stimulus and the distractor stimulus were placed on either end of the test board, at approximately 20 and $80 \%$ of the distance of the test board. The tube of the feeding apparatus was presented in a similar position to that used in the training phase (online suppl. Fig. S1). A trial commenced when the start barrier was lifted and the fish could move towards the stimuli. As in the training trials, a reward was dispensed from the feeding apparatus when the fish touched the reward stimulus with its barbels for $2-3 \mathrm{~s}$. If the distractor stimulus was touched instead of the reward stimulus the trial was terminated, and the fish did not receive a food reward in that trial. On completion of each trial the test board was removed, and fish were corralled back into the start box. The position (right or left) of the red stimulus varied each session and was never in the same position more than twice in a row to reduce any side bias. Each fish completed a total of 32 trials.

Three-Choice Discrimination Experiment: Fixed Reward Card Brightness

A three-choice discrimination experiment testing selection of the red stimulus (of a single fixed brightness) against 2 distractor stimuli of varying brightness was also done using 6 fish. By placing the reward stimulus with 2 distractors simultaneously, the odds of the fish picking the reward stimulus by chance were reduced from 50 to $\sim 33 \%$. The start barrier was deployed, placing the fish in the start area. The test board was placed into the experimental arena and 3 stimuli ( 1 reward stimulus and 2 distractor stimuli) were placed on the test board at an equal distance from each other. The start barrier was then lifted, and the fish would choose a stimulus as described above. Each fish completed a total of 24 trials each ( 8 sessions, 3 trials per session), allowing the reward and distractor stimuli to appear equally often in each of the 3 positions on the test board over the course of the experiment.

\section{Variable Reward Brightness Experiment}

A second and more challenging three-choice discrimination experiment was done on the 6 of the same individuals from the previous trials that required the fish to select 1 of 3 red reward stimuli (original, light, or dark) from 2 grey distractor stimuli of differing brightness. In this experiment the reward and distractor stimuli appeared equally often in each of the 3 positions on the test board over the course of the experiment. Each distractor stimulus was viewed twice in each of the 3 positions. In each session, the red stimulus was placed in a different position (left, middle, or right). The fish completed a total of 32 trials each ( 12 sessions, 3 trials per session). 


\section{Statistical Analysis}

General linear mixed models (GLMMs) with a binomial distribution and log link function were used to determine whether the observed choice frequency of the reward stimulus differed significantly from chance. We first ran a model to include the side that fish chose to account for any side bias. Two-choice trials included two levels (left or right) while three-choice trials included three levels (left, middle, and right). The models were constructed with a choice of reward stimulus (correct or incorrect) as the dependent variable and side of choice as a fixed effect. Fish identity was included as a random factor. Models were built in $\mathrm{R}$ (version 1.3.959, RStudio Inc., Boston, MA, USA) using the glmer function in the lme4 package [Bates et al., 2015]. As no side bias was observed in any of the experiments, null models were constructed with reward stimulus choice as the dependent variable and fish identity as a random effect. For the variable brightness experiment, we also included the reward stimulus (light, original, or dark) as a fixed effect. Models were assessed for overdispersion.

To assess the performance of the fish against each of the 8 distractor cards, we aggregated the correct and incorrect choices for each distractor card. We then constructed 8 separate GLMMs, each using a subset of each trial that had a particular distractor card present. For each test, the fish choice (correct or incorrect) was included as the response variable and fish identity as a random effect. Data from each trial were used only once, and fish identity was included as a random effect to control for the repeated measure aspect of the design. We obtained confidence intervals using the confint function in R [R Core Team, 2020]. The logits for the intercept and confidence intervals were converted to probability. In the two-choice experiment we assessed the correct choice against a $50 \%$ probability, and in the three-choice trials we assessed the proportion of correct choices against a $33 \%$ probability.

\section{Modelling the Appearance of Goatfish Bands}

We used visual models to estimate if there were perceivable spectral differences in the red and white body colour displayed by goatfish, as viewed by conspecifics. Spectra from 5 individuals were measured using a JAZ EL-200 portable spectrophotometer (boxcar width $=10$, integration time $=20 \mathrm{~ms}$, scans to average $=$ 50; Ocean Insight Pty. Ltd.) with a PX-2 pulsed xenon light source. Prior to measurement we immobilised the fish by anesthetising them with a light dose of the fish anaesthetic MS222 $\left(50 \mathrm{mg} \mathrm{L}^{-1}\right.$; Sigma; 1:2,000) buffered with sodium bicarbonate $\left(\mathrm{NaHCO}_{3}\right)(25$ $\left.\mathrm{mg} \mathrm{L}^{-1}\right)$. Reflectance was calibrated against a $99 \%$ white standard between measurements (Ocean Insight) [Dalrymple et al., 2015], and the bifurcated probe, containing both light delivery and collecting fibres, was fixed at a distance of $2 \mathrm{~cm}$ from the surface of the body, and an angle of $45^{\circ}$ to minimise specular reflection. All measurements were carried out in a dark room, making the probe the only available light source. The reflectance spectra were processed with OceanView Spectrometer Operating Software (version 2.0.7). We took 3 reflectance spectra of each goatfish from 300 to $700 \mathrm{~nm}$. Data were binned into 1-nm wavelength intervals and measurements subsequently averaged for each individual.

To predict whether and under what conditions the red and white coloured bands on goatfish may be distinguishable to conspecifics, we again used the log-linear form of the receptor noise limited model [Vorobyev et al., 1998], parameterised as above. Here, however, we used a bootstrapping procedure to attain $95 \%$ confidence intervals (CIs) for noise-weighted colour $(\Delta S)$ and luminance $(\Delta \mathrm{L})$ distances between patches [Maia and White, 2018]. To ascertain whether $U$. lineatus could discriminate between the coloured bands of conspecifics in representative coastal environments, we reran the model using downwelling irradiance measurements collected in mesotrophic coastal waters at depths of 3, 6, 10, 13 , and $16 \mathrm{~m}$ [as described in Savelli et al., 2018]. As is predicted by the receptor-noise model, we consider colour $(\Delta S)$ and luminance $(\Delta \mathrm{L})$ distances of 1 to represent a likely threshold below which two stimuli are unlikely to be reliably discriminated by a viewer. Empirical work continues to show that while such a threshold value is broadly supported it can vary across ecological contexts and visual channels [Sibeaux et al., 2019; van den Berg et al., 2020], which we remain mindful of when interpreting our results. All spectral processing and visual modelling were conducted in $\mathrm{R}$ (v 4.0.2) [R Core Team, 2020] using the package pavo [Maia et al., 2019].

Table 1. Spectral characteristics of rod and cone visual pigments in the retina of $U$. lineatus measured using microspectrophotometry

\begin{tabular}{lllll}
\hline & Rod & SWS & DC1 & DC2 \\
\hline$\lambda_{\max }$ of mean prebleach spectrum, nm & 501.3 & 412.1 & 493.8 & 524.2 \\
Mean prebleach $\lambda_{\text {max }}, \mathrm{nm}$ & $501.3 \pm 3.8$ & $412.8 \pm 5.4$ & $494.6 \pm 6.9$ & $523.6 \pm 10.2$ \\
$\lambda_{\max }$ of mean difference spectrum, nm & 507.4 & 404.2 & 495.3 & 524.6 \\
Mean difference spectrum $\lambda_{\max }, \mathrm{nm}$ & $507.1 \pm 9.8$ & $416.8 \pm 29.6$ & $495.5 \pm 8.1$ & $523.4 \pm 15.1$ \\
Absorbance change at $\lambda_{\max }$ of difference spectrum & 0.0037 & 0.0091 & 0.0050 & 0.0035 \\
Number of cells averaged & 43 & 6 & 46 & 51 \\
\end{tabular}

Fig. 4. Microspectrophotometric measurements of the retinal photoreceptor visual pigments in the bluelined goatfish $U$. lineatus. a, c, e, $\mathbf{g}$ Normalised prebleach (black circles) and postbleach (open circles) absorbance spectra. b, d, f, h Bleaching difference spectra. Prebleach and difference spectra are shown overlaid with an $\mathrm{A}_{1}$ (rhodopsin) template with a $\lambda_{\max }$ at that of the mean spectrum (which is similar to but distinct from the mean $\lambda_{\max }$ value reported in Table 1 and the text) in each case (solid black line). Postbleach spectra are fitted with a variable point running average.

(For figure see next page.) 


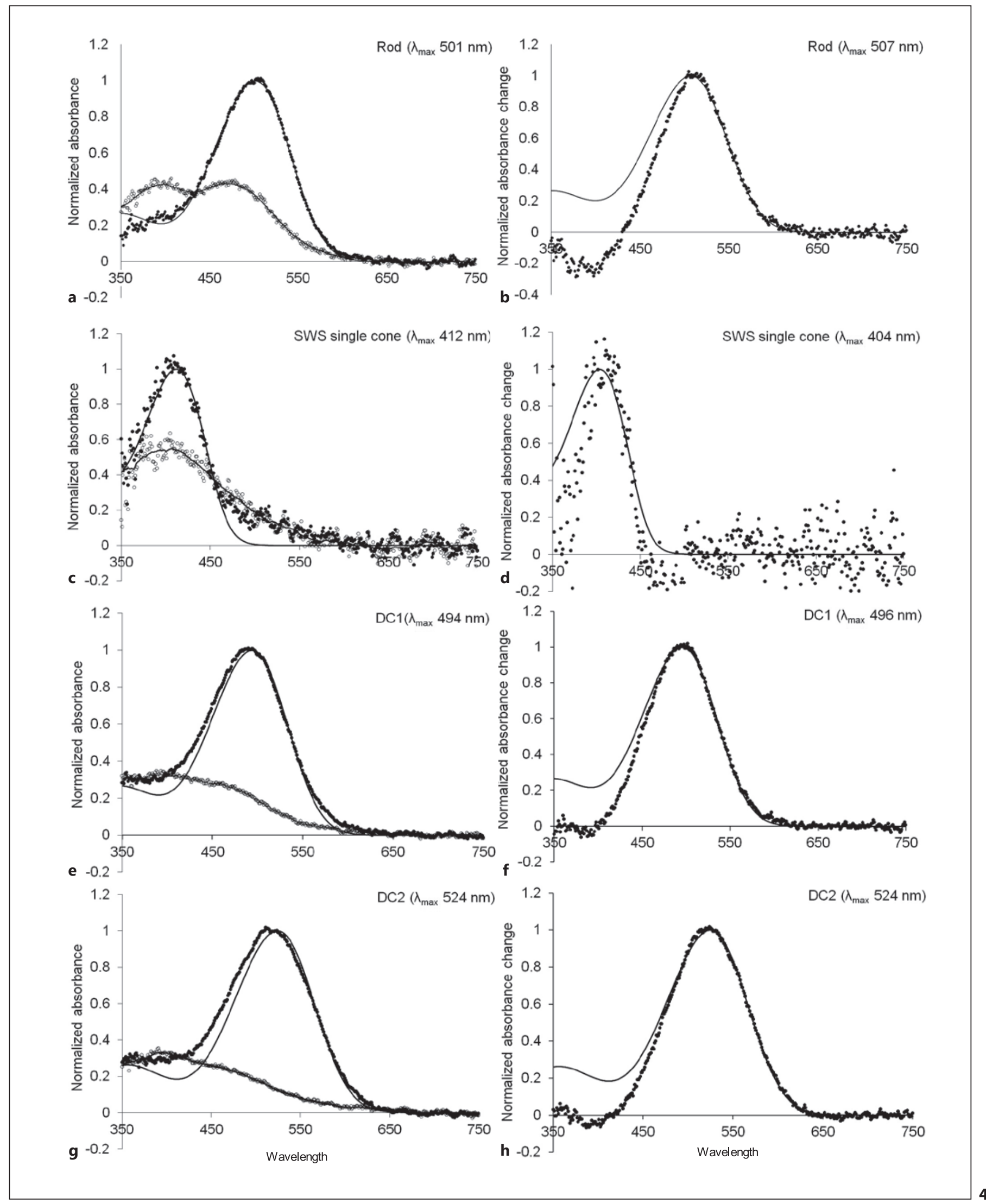

Goatfish Vision and Body Colouration 


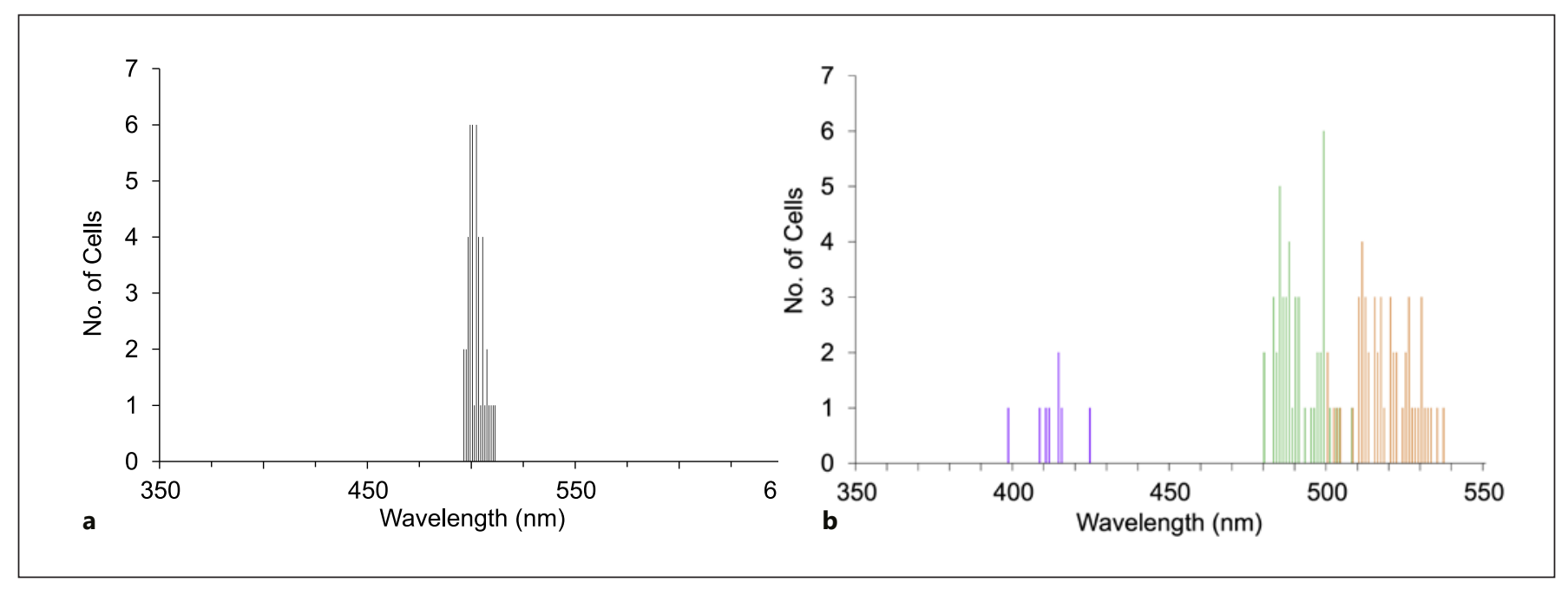

Fig. 5. Spectral distribution of the wavelengths of maximum absorbance $\left(\lambda_{\max }\right)$ of the visual pigments measured in $\operatorname{rod}(\mathbf{a})$ and cone (b) photoreceptors in the retina of $U$. lineatus. In $\mathbf{b}$, the range of $\lambda_{\max }$ values for the SWS single cones (purple bars), DC1 (green bars), and DC2 (orange bars) double cone members are indicated by horizontal bars.

\section{Results}

\section{Microspectrophotometry}

The retinae of the adult $U$. lineatus examined contained both rods and cones and were therefore duplex in terms of anatomy. More than 800 absorbance spectra were obtained, with 146 acceptable scans retained for further analysis, providing a reasonably high confidence that most or all of the photoreceptor classes present in the retina were sampled. The microspectrophotometric data for U. lineatus are summarised in Table 1 and Figure 4. On the basis of goodness-of-fit of the rod spectra to visual pigment templates [Govardovskii et al., 2000], all photoreceptor absorbance spectra were considered to represent rhodopsin (vitamin $\mathrm{A}_{1}$-based) visual pigments. Some cone spectra were broader than the fitted $A_{1}$ template, which could indicate the presence of low levels of the $A_{2}$ chromophore or, as seems more likely based on the data and findings in other marine teleosts, co-expression of multiple visual pigments within the same outer segment.

$T$ The retina of $U$. lineatus contained a single type of rod identified by their long, cylindrical outer segments, which had a mean $( \pm S D)$ length of $19 \pm 4.3 \mu \mathrm{m}$ and diameter of $1.78 \pm 0.3 \mu \mathrm{m}$ and contained an MWS visual pigment with a mean $( \pm S D) \lambda_{\max }$ at $501 \pm 3.8 \mathrm{~nm}$ (Fig. $4 \mathrm{a}, \mathrm{b}$ ). The retina also contained a large population of cones that was dominated by a class of double cones comprising two morphologically distinct member cones. Hereafter, we refer to the two members of the double cone pair as DC1 and DC2. The outer segment of the DC1 member had a mean $( \pm$ SD) base and tip diameter of $3.0( \pm 0.08)$ and $1.5( \pm 0.05)$ $\mu \mathrm{m}$, respectively, a mean length of $9.5( \pm 0.39) \mu \mathrm{m}$ and contained an MWS visual pigment of variable $\lambda_{\max }$ between 483 and $508 \mathrm{~nm}$, with an overall mean $( \pm S D)$ of $495 \pm 6.9 \mathrm{~nm}$ (Fig. 4e, f). The outer segment of the DC2 member had a mean base and tip diameter of $2.5( \pm 0.07)$ and $1.5( \pm 0.05) \mu \mathrm{m}$, respectively, a mean length of 8.5 $( \pm 0.37) \mu \mathrm{m}$ and contained an MWS visual pigment of variable $\lambda_{\max }$ between 497 and $537 \mathrm{~nm}$, with a mean of 524 $( \pm 10.2) \mathrm{nm}$ (Fig. 4g, h). The mean difference between the $\lambda_{\max }$ values of the two members of the same intact double cone pair (i.e., DC1 vs. DC2) was $27( \pm 11.3) \mathrm{nm}$; the largest difference measured between the members was $46 \mathrm{~nm}$. Inspection of $\lambda_{\max }$ histograms (Fig. 5b) showed considerable spread in $\lambda_{\max }$ measured in the double cone outer segments. This suggested that more than one opsin may be expressed in each photoreceptor outer segment.

The retina also contained a class of single cones, with outer segments that were shorter and narrower than the individual members of the double cones, having a mean base and tip diameter of 2 and $1 \mu \mathrm{m}$, respectively, and a mean length of $6 \mu \mathrm{m}$. The outer segments of this cone class contained a short-wavelength ("violet") sensitive (SWS) visual pigment with a mean $\lambda_{\max }$ of $412 \mathrm{~nm}$ (fig. 4c, d). We occasionally measured single cones that had visual pigments with $\lambda_{\max }$ values within the same wave- 


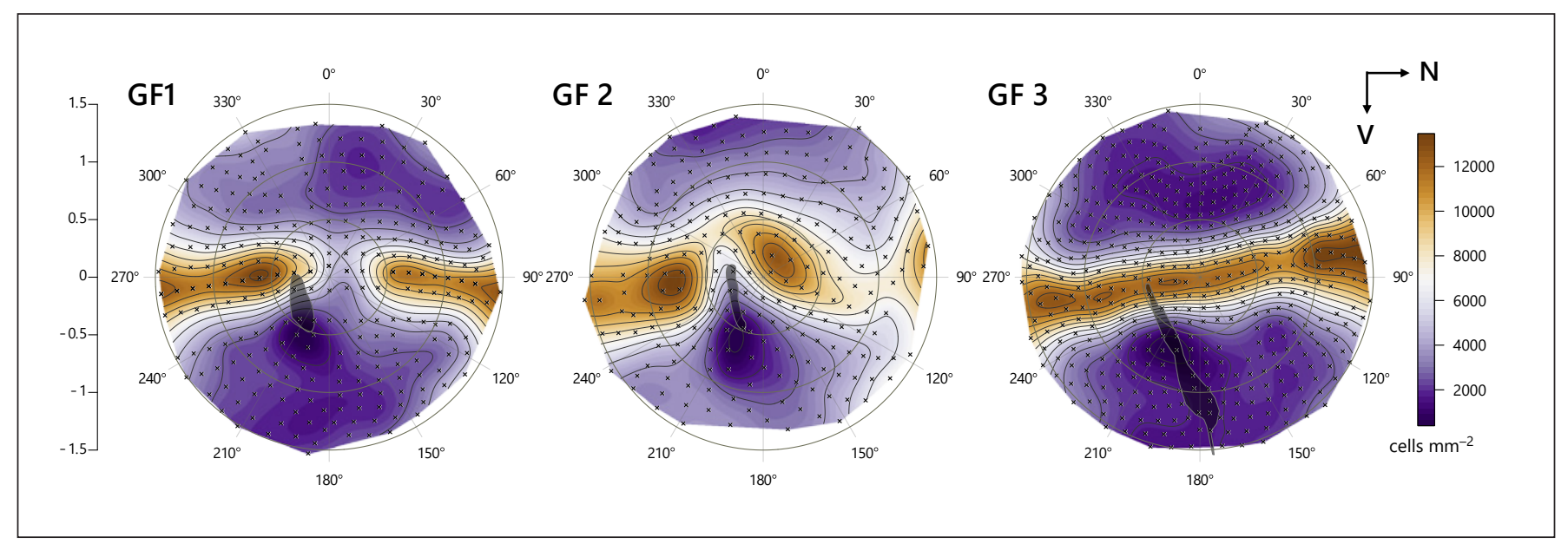

Fig. 6. Isodensity map of the right eye of 3 U. lineatus GF1-GF3. Topography of retinal ganglion cell layer for 3 individual goatfish (right retinas). The cell density was highest in the centre, forming a horizontal streak.

length range as those found in the double cones, and it is possible that these rarer cones represent a discrete MWS single cone type. It is also plausible, however, that they are detached individual members of double cones. We have presented these data in the online supplementary material (suppl. Fig. S3).

The rod and SWS single cone absorbance spectra (Fig. 4) were fitted well by an all- $\mathrm{A}_{1}$ visual pigment template. Furthermore, given marine fish generally possess only $A_{1}$ chromophores [Toyama et al., 2008], it is likely that the spread in double cone $\lambda_{\max }$ values was not due to a mixture of $A_{1}$ and $A_{2}$ chromophores in the outer segment, although we cannot rule out cone class-specific modulation of chromophore ratios. At this stage it was not possible to say with any certainty how many different opsin types are expressed in the double cones, which will require sequencing of the genes present in the goatfish genome and/or expressed in the retina.

\section{Anatomical Measurements of Visual Acuity}

Three retinas from the right eyes of fish were examined to establish visual acuity and areas of highest cell density. The mean peak RGC density across the three fish was $16,533( \pm 1,686)$ cells $\mathrm{mm}^{-2}$, and the acuity estimate from this is 6.2 cycles per degree (cpd). The average peak photoreceptor density for the three fish was 50,967 $( \pm 10,942)$ cells $\mathrm{mm}^{-2}$ with acuity estimated at $10.2 \mathrm{cpd}$. The topographic maps (Fig. 6) indicate a broad horizontal streak extending across the horizontal meridian with some areas of increased ganglion cell density in a putative area cen- tralis and in the temporal region of the retina. Examination of the photoreceptors in areas of high $(>13,500$ RGCs $\left.\mathrm{mm}^{-2}\right)$ and low $\left(<5,000\right.$ RGCs $\left.\mathrm{mm}^{-2}\right)$ density cell counts found an average of $190.7( \pm 16.7$ SE) and $492.7( \pm 27.1)$ cone photoreceptors, respectively. The average convergence ratios (photoreceptor:RGC) were 3.0:1 in the highest cell density regions and 6.2:1 in the low cell density regions of the retina.

\section{Spatial Resolving Distances}

A value of spatial acuity of $6.2 \mathrm{cpd}$ means that one justresolvable cycle will subtend an angle of $0.162^{\circ}$. If one cycle of the banding pattern on the fish is $20 \mathrm{~mm}$ (i.e., one light and dark stripe), then this becomes unresolvable beyond a distance of $20 / \tan (0.162)=7,074 \mathrm{~mm}($ or $\sim 7 \mathrm{~m})$ (Fig. 7).

\section{Behavioural Experiments}

Quantum catches of the original, light and dark red reward stimuli were most similar to the grey distractor stimuli 2, 3 and 1, respectively. Distractor stimuli 4-8 provided additional brightness distractors. The achromatic distances between reward and distractor stimuli were all greater than our assumed threshold of $\Delta \mathrm{L}=1$ with the exception of the light reward card and distractor stimulus $4(0.59 \Delta \mathrm{L})$ and the dark reward card and distractor card $2(0.14 \Delta \mathrm{L})$. See supplementary material for all chromatic and achromatic pairwise distances between stimuli (online suppl. Table S1). 


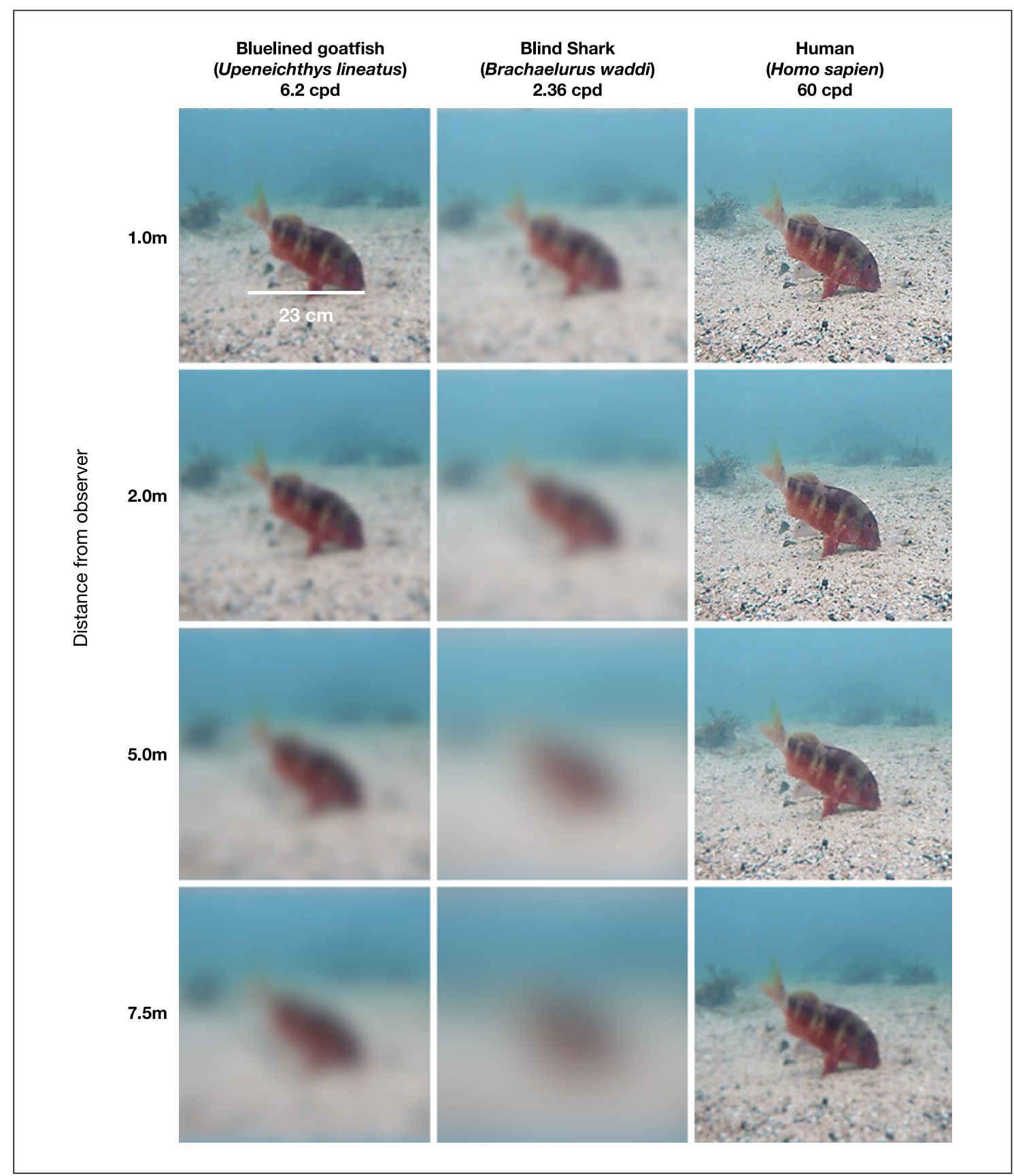

Fig. 7. U. lineatus displaying the red-banded colouration and how it may appear from 4 different viewing distances in metres to a conspecific, as well as a blind shark and human for comparison. Column headings show acuity in cycles per degree. Image generated using AcuityView package in R.

Two-Choice Discrimination Experiment: Fixed Reward Card Brightness

In the two-choice discrimination experiment fish chose the red reward card correctly $77.2 \%$ of the time $(95 \% \mathrm{CI}=$ 68.4-85.2), which was significantly greater than by chance
(50\%). There was no effect of the side of the test board that the fish selected $(p=0.070)$. The fish were able to distinguish the reward card against all 8 distractor cards (Fig. 8). On average fish took $3.37 \mathrm{~s}( \pm 0.16 \mathrm{SE})$ to make their choice with the longest choice taking $12 \mathrm{~s}$. 
Fig. 8. Proportion of correct choices (with $95 \%$ confidence intervals) for original red reward stimulus in the two-choice discrimination trials against each of the grey distractor stimuli. Black dots and error bars show proportions and 95\% confidence intervals obtained from GLMMs. Grey dots are the proportion of correct choices for individual fish. The dotted line represents the $50 \%$ chance level.

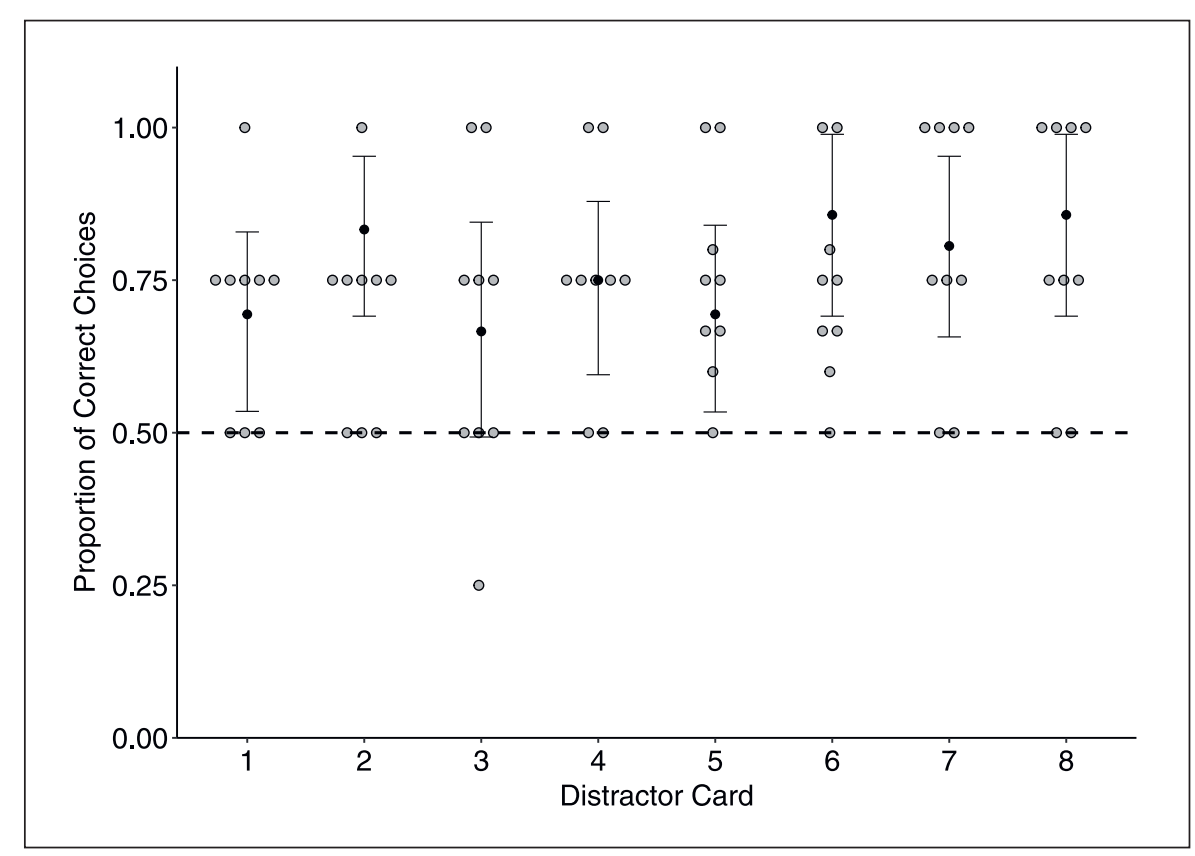

Three-Choice Discrimination Trial: Fixed Reward

\section{Card Brightness}

In the three-choice experiment fish chose the red reward stimuli $79.2 \%$ of the time, significantly more times than would be expected by $33 \%$ chance $(95 \% \mathrm{CI}=66.8-$ 89.0 ). No side bias was evident, with no significant difference between the number of taps made by the fish on the left and middle ( $p=0.815)$, left and right sides $(p=0.641)$, or right and middle $(p=0.927)$ of the test board. Fish took $3.16( \pm 0.22 \mathrm{SE}) \mathrm{s}$ on average to make their choice with the longest choice taking $14 \mathrm{~s}$. Again, in the three-choice discrimination trial the fish distinguished the reward stimulus against the 8 distractors significantly more times than expected by chance (Fig. 9).

Variable Reward Brightness Experiment

Overall, the fish chose the correct stimuli $58.9 \%$ of the time (95\% CI $=41.6-77.1)$. There was no side bias, with no significant difference between the middle and left $(p=$ $1.000)$, right and left ( $p=0.975)$, or the right and middle sides $(p=0.979)$. On average fish took $4.75 \mathrm{~s}( \pm 0.72 \mathrm{SE})$, with the longest decision taking $13 \mathrm{~s}$. When success was assessed for each reward card against the distractor stimuli, however, the fish could not always distinguish the red reward stimulus against each of the 8 distractors and often struggled to discriminate the reward stimulus from the very brightest or the very darkest of the grey distractors (Fig. 10).

\section{Modelling the Appearance of Goatfish Bands}

The red bands of goatfish are characterised by a sigmoidal-type reflectance rich in longer wavelengths (600$700 \mathrm{~nm}$ ), with an inflection point at approximately 590 $\mathrm{nm}$. The white bands, by contrast, are comparatively flat across most of the visible range $(330-700 \mathrm{~nm})$. Both red and white stripes exhibit a smaller, secondary reflectance peak in the ultraviolet (approx. $350 \mathrm{~nm}$ ), however, which strongly suggests the contribution of both pigments (such as carotenoids) and nanostructures (such as purine or guanine platelets) to colour production and colour change [Shawkey and D'Alba, 2017]. With respect to the question of appearance, our visual models suggest that adjacent bands should be discriminable by conspecifics on the basis of both colour and luminance across a range of habitats. The average chromatic distance $(\Delta S)$ between red and white bands ranged from 2.3 to 2.6 at $3.3 \mathrm{~m}$ and 16.6 $\mathrm{m}$, respectively, while the average achromatic distances $(\Delta \mathrm{L})$ were considerably larger at 21.0 and 21.8 at the same depths (online suppl. Table S2). These values were consistent and remained above threshold $(\Delta \mathrm{S}=\Delta \mathrm{L}=1)$ across the full depth gradient, which suggests the banding pattern is potentially distinguishable by the goatfish under a range of natural conditions (see online suppl. Video S1 for animated depth model). 
Fig. 9. Proportion of correct choices (with $95 \%$ confidence intervals) for original red reward stimulus in the three-choice discrimination trials against each of the grey distractor stimuli. Black dots and error bars show proportions and 95\% confidence intervals obtained from GLMMs. Grey dots are the proportion of correct choices for individual fish. The dotted line represents the $33 \%$ chance level.

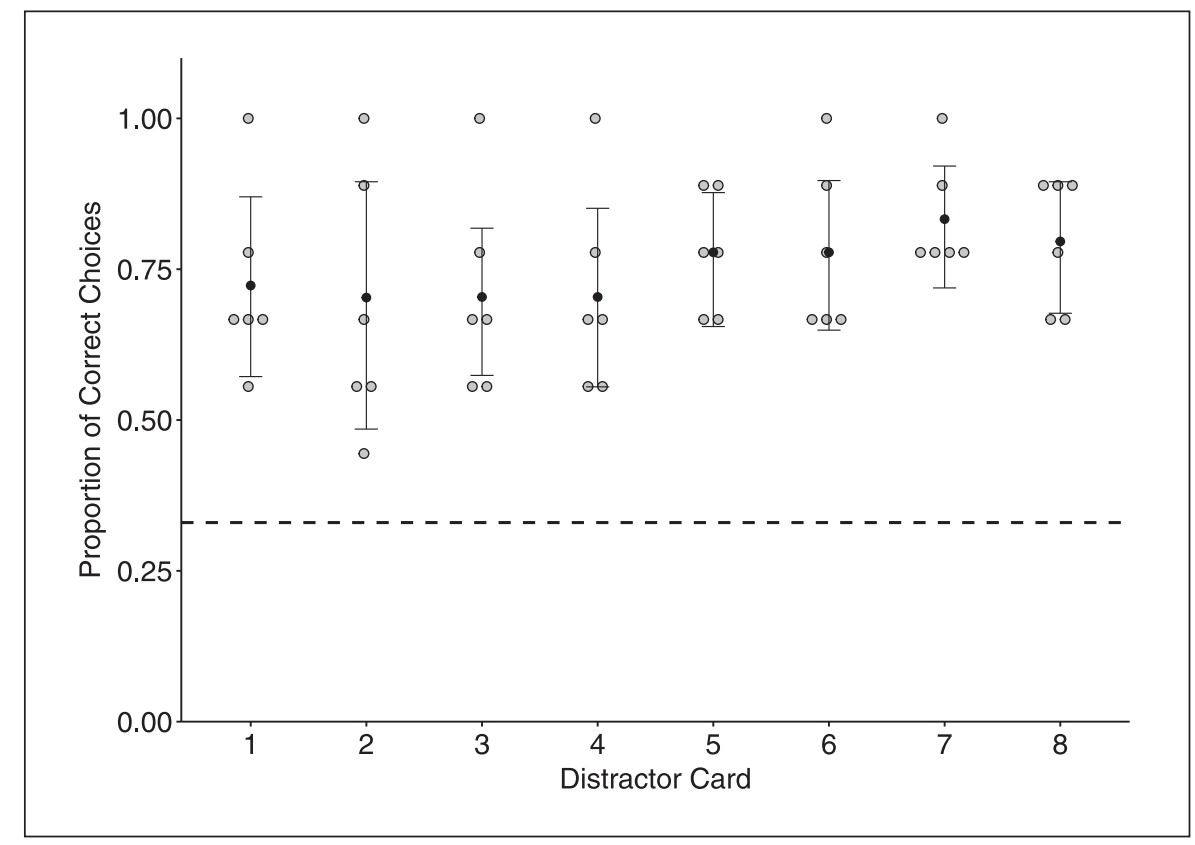

\section{Discussion}

This study demonstrates that $U$. lineatus have the potential for colour vision and the ability to distinguish the colour red. Results from microspectrophotometry showed that $U$. lineatus have at least three spectrally distinct cone visual pigments. Based on the spread of $\lambda_{\max }$ values measured in the double cones, it is likely that multiple opsins are expressed (and possibly co-expressed) in the outer segments. There was no evidence for a dedicated "red-sensitive" LWS pigment (the longest $\lambda_{\max }$ recorded was $534 \mathrm{~nm}$ ), but it is possible that the broad absorbance spectrum of the double cones provides meaningful visual sensitivity to longer wavelengths. Results obtained from the colour discrimination experiments confirmed that $U$. lineatus can discriminate a red reward stimulus from a range of grey distractor stimuli of different brightness. Furthermore, when presented with red stimuli of variable brightness, they could mostly discriminate the lighter and darker red stimuli from the grey distractors.

Investigation into spatial resolution of $U$. lineatus found that anatomical estimates of acuity were $6.2 \mathrm{cpd}$ and the distance that the bands become unresolvable is calculated at around $7 \mathrm{~m}$. The chromatic distances $(\Delta S)$ between the red and white colour bands of a single specimen of $U$. lineatus were above 2 at all water depths modelled, suggesting sufficient perceptual "distance" between the two colours to allow discrimination when red light is available. The calculated values are close to threshold and depend, in part, on the actual but currently unknown photoreceptor ratios and Weber fractions of the cone photoreceptors of $U$. lineatus. The irradiance measurements used were measured in the North Pacific Ocean and thus not from where $U$. lineatus reside, but are representative of temperate, mesotrophic waters [Savelli et al., 2018] (online suppl. Fig. S4). Given short-term changes in irradiance in any coastal water body due to tides, rainfall, etc., they were deemed sufficient to provide an insight into the likely detectability of the body pattern. The achromatic contrast of adjacent bands was much greater than their chromatic contrast, suggesting that if the rapid colour change exhibited by $U$. lineatus is indeed a signal it may be the contrasting brightness of the bands alone. Nonetheless, reviewing the microspectrophotometric and behavioural results together, it seems likely that $U$. lineatus have functional colour vision and, where red wavelengths of light are available, can discriminate their red body colouration under photopic conditions.

Microspectrophotometry identified a single rod pigment and at least 3 spectrally distinct cone visual pigments in the retina of $U$. lineatus. The $\lambda_{\max }$ of the rod visual pigment $(501 \mathrm{~nm})$ puts it within the range of $\operatorname{rod} \lambda_{\max }$ values (approx. 490-510 $\mathrm{nm}$ ) reported in a number of teleost fishes inhabiting coastal marine environments $(<50 \mathrm{~m}$ depth) [Lythgoe and Partridge, 1989]. As seen in many teleosts [Schweikert et al., 2018], the SWS single cones of 
Fig. 10. Results for experiment 3 showing the average percent of correct choices against each of the grey distractor stimuli for the 5 fish for the lighter red stimulus, the original red stimulus and the darker red stimulus. Black dots and error bars show proportions and 95\% confidence intervals obtained from GLMMs. Grey dots are the proportion correct for individual fish. The dotted line represents the $33 \%$ chance level.

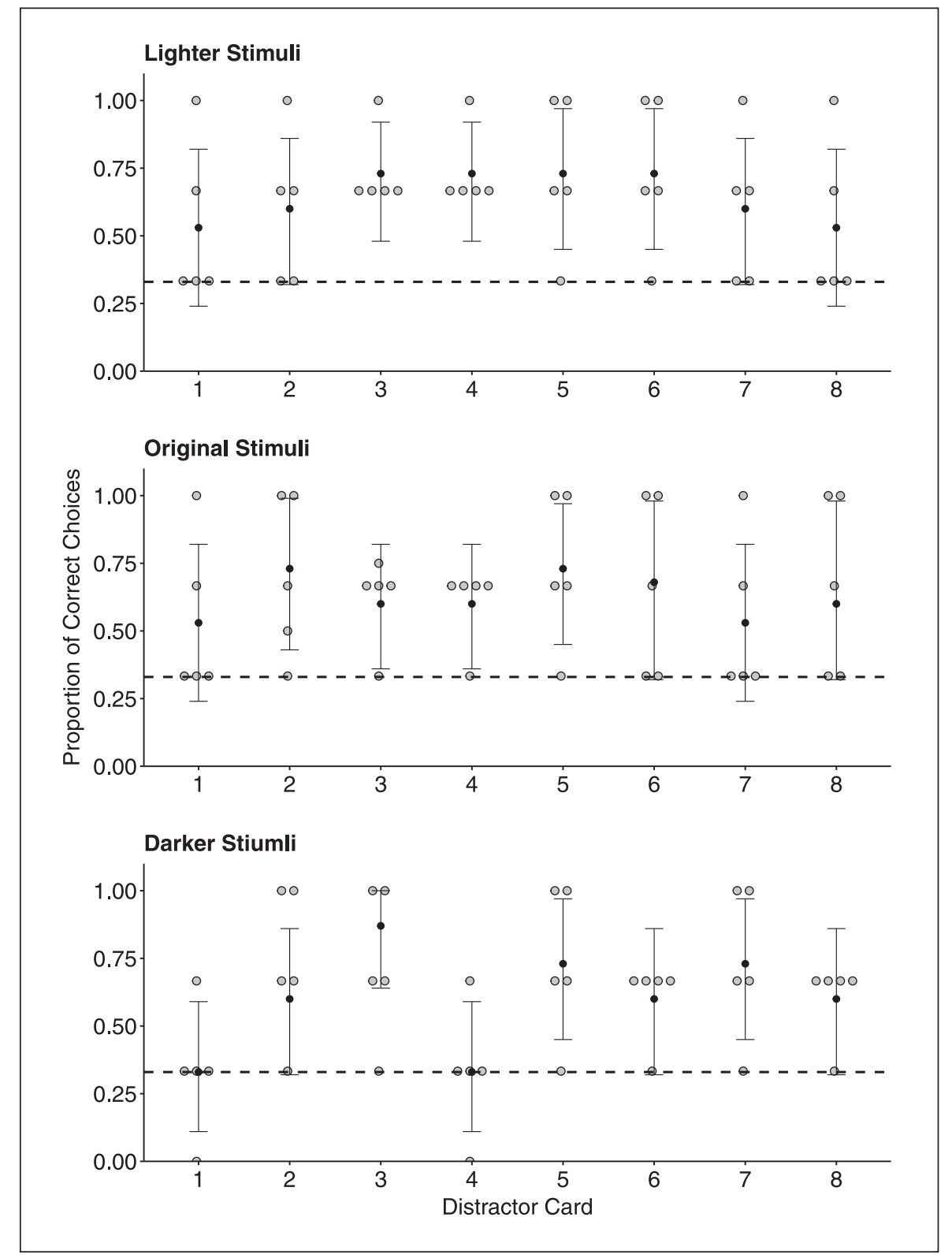

Table 2. Microspectrophotometric measurements of visual pigments in $U$. lineatus and 4 other species of goatfish

\begin{tabular}{|c|c|c|c|c|c|}
\hline Bluelined goatfish & Upeinichthys lineatus & 501 & 412 & 494 & 524 \\
\hline Bartail goatfish & Upeneus tragula & & & 506 & 530 \\
\hline Yellowstripe goatfish & Mulloicichthys flavolineatus & 486 & 366 & 480 & 523 \\
\hline Banded goatfish & Parupeneus multifasceatus & 494 & & 489 & 518 \\
\hline Red mullet & Mullus barbatus & 497 & & 491 & 533 \\
\hline
\end{tabular}

The visual pigments described in this study for $U$. lineatus are in bold. 
$U$. lineatus (mean $\lambda_{\max }$ of $413 \mathrm{~nm}$ ) were sensitive to much shorter wavelengths than the double cones $\left(\lambda_{\max }\right.$ of 494 and $524 \mathrm{~nm}$ in the DC1 and DC2 members, respectively). Microspectrophotometric measurements of retinal visual pigments have been made previously in four other species of goatfish: the red mullet (Mullus barbatus), the bartail goatfish (Upeneus tragula) [Shand, 1993], the yellowstripe goatfish (Mulloicichthys flavolineatus), and the banded goatfish (Parupeneus multifasceatus) [Govardovskiii and Zueva, 1988; Losey et al., 2003] (Table 2).

Adult $U$. tragula, which can sometimes be found in similar environments to $U$. lineatus (Tosetto; pers. observations) have non-identical double cones similar to those of $U$. lineatus, but with visual pigments peaking at longer wavelengths and no absorbance data recorded for single cones [Shand, 1993]. Given the measurements for the $U$. tragula were made from just one individual, however, it is possible that some cone types were missed. Mulloicichthys flavolineatus and P. multifasceatus, which are both reef-dwelling fish, possess rods with short-wave-shifted $\lambda_{\max }$ values compared to $U$. lineatus, and $M$. flavolineatus has a single cone pigment that is maximally sensitive in the UV [Losey et al., 2003]. However, both M. flavolineatus and P. multifasceatus have double cones with spectrally distinct pigments and with spectral sensitivities similar to that of $U$. lineatus. M. flavolineatus and $P$. multifasceatus occupy similar depths to U. lineatus $(<100 \mathrm{~m})$, but they typically inhabit inshore tropical reefs [Losey et al., 2003] rather than the temperate coastal areas inhabited by U. lineatus. Coastal dwelling teleosts generally "tune" their double cone visual pigments towards longer wavelengths compared to oceanic or outer shelf dwelling animals, but in the case of these goatfishes, their pigments appear to be tuned to bluer waters and do not fit the typical pattern described by Lythgoe [2003]. M. barbatus, which is demersal, occurring up to $300 \mathrm{~m}$ depth, also possesses spectrally distinct double cone pigments that are most similar to those of $U$. lineatus. The similarities in double cone pigments across the Mullidae inhabiting different environments raises interesting questions about the tuning of receptors in goatfish and highlights that further work is required into the visual ecology of this taxon to understand these differences.

It is possible that $U$. lineatus are using the members of the double cones independently to discriminate colour. Traditionally, only single cones were thought to contribute to colour vision, with the double cone summation hypothesis suggesting double cones mediate achromatic tasks such as luminance, polarisation, and motion [Hawryshyn et al., 2001] rather than discriminate between co- lours. Until recently, if fish had three distinct visual pigments but two of them were expressed in different members of double cones, the fish were still considered dichromats [Marshall and Vorobyev, 2003]. However, behavioural assays in Picasso triggerfish (Rhinecanthus aculeatus) suggest that signals from spectrally distinct members of the double cone pair can be used as independent spectral channels to provide chromatic information [Pignatelli et al., 2010]. The mean difference between the two members of the double cones in the triggerfish are reported to be $50 \mathrm{~nm}$ (one member at $\lambda_{\max } 480 \mathrm{~nm}$ and the other at $\lambda_{\max } 530 \mathrm{~nm}$ ). This is consistent with the largest difference between double cone members in $U$. lineatus $(47 \mathrm{~nm})$. By way of comparison, the peak sensitivities of human green- $\left(\lambda_{\max } 531 \mathrm{~nm}\right)$ and red-sensitive $\left(\lambda_{\max }\right.$ $558 \mathrm{~nm}$ ) cones are separated by just $27 \mathrm{~nm}$ [Dartnall et al., 1983]. Interestingly, Picasso triggerfish ( $R$. aculeatus), which also lack a dedicated red-sensitive visual pigment, can discriminate orange and red colours against a range of brightness distractors [Cheney et al., 2013]. Given that $U$. lineatus have double cones with similar peak sensitives to $R$. aculeatus, and also demonstrated the ability to distinguish the colour red, it is possible that they too are able to use double cones for colour discrimination and possess trichromatic colour vision.

To confirm the neural basis for colour vision, it is necessary to show that an animal can use spectral information encoded by the outputs from spectrally distinct photoreceptors. In the colour choice experiments, $U$. lineatus could successfully discriminate a red reward stimulus from grey distractor stimuli of varying brightness in both two-way and three-way choice discrimination tasks. In general, they performed these tasks successfully, and reliably selected the red reward stimulus. When the brightness of the red reward stimulus also varied, however, the performance of the fish deteriorated. It is possible that the fish had learnt the absolute brightness of the reward stimulus instead of hue and were then unable to generalise to other brightness levels of this stimulus. However, if this were the case then the performance of the fish when discriminating the original red reward card from the distractors should have been as high as in the initial two- and three-way choice experiments, which was clearly not the case (Fig. 8-10). It may also have been that performance or motivation deteriorated with ongoing captivity, or simply that the task was much harder. Nevertheless, fish still chose the correct card in the variable brightness experiment significantly more times than by chance and, taken with the fixed brightness tests, we consider this strong evidence for chromatic vision and the ability to discriminate red objects. 
The visual acuity of $U$. lineatus was estimated to be 6.2 cpd with a distinct horizontal streak across the centre of the retina. Based on these acuity estimates, the vertical bands of a medium-sized fish could be resolved at a maximum range of approximately $7 \mathrm{~m}$ in clear water. Horizontal streaks are often found in pelagic species, or those inhabiting sandy bottoms. These streaks provide the animal with the capacity to scan the horizon at higher resolution without saccadic eye movements. Given that U. lineatus spend time foraging in exposed sandy areas adjacent to the protection of rocky reefs, the streaks may provide an advantage in identifying predators or conspecifics [Collin and Pettigrew, 1988]. It is difficult to make comparisons of acuity to fish that have a similar ecology to $U$. lineatus, since the majority of acuity estimates have been obtained for coral reef and pelagic species [Caves et al., 2018a] and not for temperate species in sandy habitat. Two fish that inhabit temperate systems and feed in the benthos are eastern school whiting (Silago flindersi) and snapper (Pagrus auratus) both with estimated acuities of $9 \mathrm{cpd}$, although these estimates were based on photoreceptor counts rather than ganglion cells [Caves et al., 2017]. Ganglion cell counts were used to estimate visual acuity for dusky flathead (Platycephalus fuscus) and southern bluespot flathead (Platycephalus speculator), both of which are coastal temperate species. Their acuity estimates of 8.1 and $9.9 \mathrm{cpd}$, respectively [Seward, 2018], are higher than those of goatfish, possibly because flathead are ambush predators and rely on finer acuity for feeding. Without conducting behaviourally relevant trials it is difficult to make conclusions about the spatial resolution of $U$. lineatus. Anatomical estimates of acuity provide a theoretical upper limit of vision [Caves et al., 2018a], and comparative acuity studies often find behavioural estimates of acuity are lower than those obtained anatomically [Champ et al., 2014; Parker et al., 2017]. In $U$. lineatus convergence ratios of photoreceptors to ganglion cells of highest density areas were 3:1. Given that displaced amacrine cells were inevitably included in the counts of ganglion cells, it is likely that functional acuity is less than the anatomical estimates. Goatfish are regularly found feeding on infauna at the reef-sand interface or around $3 \mathrm{~m}$ from the shelter of the reef [Ross et al., 2007], even if their spatial resolving distance is less than predicted here, it may still be adequate as a intraspecific signal.

The chromatic distance between the red and white colour bands of $U$. lineatus was around $2 \Delta S$ at depths from 3 to $16 \mathrm{~m}$, suggesting that there may be sufficient perceptual "distance" between the two colours to allow discrim- ination when red light is available. Red colouration is widely used by many animals in visual signalling [Pryke and Griffith, 2006; Fitze et al., 2009]. In teleost fish, bright orange spots on male guppies (Poecilia reticulata) may be used to signify foraging ability and fitness [Grether et al., 2001], and in sticklebacks (Gasterosteus aculeatus) females use red colouration of males as a factor in mate choice [Wedekind et al., 1998]. In both cases the colouration is carotenoid pigment based but in guppies the orange spots also contain endogenous red pteridine pigments (drosopterins) [Grether et al., 2001]. While carotenoid pigments are widely reported to be a condition-dependent indicator of the health, status, and/ or condition of the fish [Svensson and Wong, 2011], there is also work supporting the potential for condition-dependent expression of structural colouration [White, 2020]. This suggests that irrespective of whether U. lineatus colour is chiefly pigment based or structural (or, as is likely, both), the red colouration displayed by U. lineatus may be reflecting the individual quality of individuals. Whether $U$. lineatus display any fluorescence in deeper water was not assessed in this study. Peak emission of red fluorescence in fish is around $600 \mathrm{~nm}$, and many fish that produce their own red luminescence also have the visual pigments to see it [Michiels et al., 2008]. Given there was no evidence of red fluorescence, nor were there pigments absorbing in those wavelengths, it is unlikely $U$. lineatus are using red fluorescence at depth. The greater achromatic, relative to chromatic, distances between the bands suggests that the brightness contrast of the banding may be more readily distinguishable than the colour contrast to conspecifics. In contrast to freshwater organisms, red colouration is not as extensively used in the marine environment, and a large proportion of signalling is achromatic. Female pipefish (Syngnathus typhle) [Berglund and Rosenqvist, 2001], kelp bass (Parablabrax clathratus) [Erisman and Allen, 2005], and sand bass (Paralabrax maculatofasciatus) [Miller and Allen, 2006], for example, all adopt contrasting body colouration with dark vertical bars to signal reproductive status [Erisman and Allen, 2005]. Furthermore, on a Caribbean reef, the yellow goatfish (Mulloidicthys martinicus) and the spotted goatfish (Pseudupeneus maculatus) change their colour rapidly to appear darker to cleaner shrimp, thereby indicating their willingness to be cleaned [Caves et al., 2018b]. U. lineatus can vary the intensity of the red brightness displayed, with the darkest red observed when they are actively feeding (Tosetto et al., unpubl. results). Thus, even if there is no sensitivity to red per se it is likely that $U$. lineatus can still see the banded pattern of conspecifics when they are for- 
aging based on luminance contrast alone. The red stripes will consistently appear darker than the adjacent white skin, and so may still communicate salient information, such as individual "quality" or social status, entirely in the achromatic channel. However, if the colour red or if different shades of red can also be discriminated, as suggested by our results (online suppl. Table S2), then the complexity (i.e., information capacity) of the signal may be increased.

Fish visual systems are often reported to be influenced by the light environment the fish inhabits, however, it is likely that drivers are more complex. While a broader spectrum of light is often associated with higher visual acuity [Mosk et al., 2007], fishes from the same coral reef may have different acuities depending on foraging strategies, with ambush predators often possessing higher acuities than those that feed on sessile or slow-moving prey [Collin and Pettigrew, 1989]. And while many billfishes are reported to have relatively high acuity to provide advantage in detecting prey, Atlantic blue marlin (Makaira nigricans) have relatively low acuity, which may be an adaptation to cope with low light levels when diving [Fritsches et al., 2003]. The factors determining colour vision may be even more complex. Following an extensive review of available literature on fish colour vision, Schweikert et al. [2018] proposed five ecological factors predicting fish chromacy and confirmed that the light environment is the biggest evolutionary driver of colour vision in fish, in line with what was proposed by several earlier studies [Munz and McFarland, 1975; Loew and Lythgoe, 1978]. If the photopic environment drives the spectral sensitivities of fish, then we would expect to see similarities in visual pigments of fish inhabiting the same environments. It is possible that the photopic environment is not always the main influence as many of the studies to date have been undertaken on fish from specific light environments, such as the deep sea [Douglas et al., 1998; Warrant and Locket, 2004; Musilova et al., 2019], tropical reefs [Hart et al., 2004; Marshall et al., 2006; Siebeck et al., 2009], and open oceans [Collin et al., 2000; Loew et al., 2002; Fritsches et al., 2003]. A fish inhabiting similar environments to $U$. lineatus is the dusky flathead (Platycephalus fuscus). Dusky flathead have different spectral sensitivities to $U$. lineatus with an SWS cone $\lambda_{\max }$ at 483 $\mathrm{nm}$ and identical twin cone pigments with $\lambda_{\max }$ at $528 \mathrm{~nm}$ [Seward, 2018]. The differences observed between these flathead and goatfish suggest visual systems are influenced by more than the photopic environment they inhabit. It is possible that in more variable and dynamic aquatic environments, such as the temperate coastal areas that goatfish inhabit, the relationship between photoreceptor complement, spectral tuning, and the ambient light environment is more complex.

It is increasingly clear that the evolution of visual systems may be driven by the requirement for signal detection as well as habitat complexity and foraging strategies. Recent research found two spectrally distinct copies of the LWS cone opsin gene in coral reef labrids [Phillips et al., 2016]. Phillips et al. [2016] suggest these species may specialise in longer wavelength vision, providing them an advantage in identifying algae and understanding communication signals via body patterns on conspecifics, both of which have reflectance spectra peaks in the red $(>600 \mathrm{~nm})$ region of the spectrum. Furthermore, studies have demonstrated that many reef fishes have developed red florescence suggesting that by using a wavelength of colour invisible to other fish it can be used to enhance visual communication between conspecifics [Michiels et al., 2008]. It has also been demonstrated that the damselfish have UV facial patterns that may not be discernible by predators, thus serving as a private communication channel between individuals [Siebeck, 2004]. Perhaps the complexity of intraspecific visual signals has also influenced the evolution of $U$. lineatus visual pigments. Clearly, the physiological and behavioural basis of colour change in goatfish is worthy of further investigation.

\section{Acknowledgements}

We thank Baptiste Monier for his assistance in training and testing of the goatfish, Samuel O'Neil and Olivia Seeger for their help in obtaining spectral reflectance measurements, Josh Aldridge as well as members of Macquarie University's "Marine Ecology Group" and "The Fish Lab" for assistance with capture and husbandry of the goatfish, Anthony Seward for technical assistance, Prof. Inigo Novales Flamarique for providing the coastal irradiance data, and Andrew Allen for assistance with our statistical analyses.

\section{Statement of Ethics}

This study complied with Australian law for the care and use of animals for scientific purposes. The study design was assessed and approved by the Macquarie University Animal Ethics Committee (ARA 2016/020).

\section{Conflict of Interest Statement}

The authors have no conflicts of interest to declare. 


\section{Funding Sources}

This research was funded by the Holsworth Wildlife Research Endowment and the Department of Biological Sciences at Macquarie University.

\section{Author Contributions}

L. Tosetto, J.E. Williamson, and N.S. Hart conceived the study. L. Tosetto designed the experiment, collected the data, and analysed the results. N.S. Hart and T.E. White provided support for the data analysis and interpretation of the data. L. Tosetto drafted the manuscript. All authors were involved in the revision of the manuscript and have agreed to its final content.

\section{Data Availability}

The data sets generated and analysed during the current study are our own. Data sets are available from the corresponding author on reasonable request.

\section{References}

Bates D, Maechler M, Bolker B, Walker S. Fitting linear mixed-effects models using lme4. J Stat Softw. 2015;67(1):1-48.

Berglund A, Rosenqvist G. Male pipefish prefer ornamented females. Anim Behav. 2001;61(2):345-50.

Bowmaker JK. Microspectrophotometry of vertebrate photoreceptors. A brief review. Vision Res. 1984;24(11):1641-50.

Bowmaker JK. The visual pigments of fish. Prog Retin Eye Res. 1995;15(1):1-31.

Bowmaker JK. Visual pigments of fishes. In: Douglas R, Djamgoz M, editors. The visual system of fish. Dordrecht: Springer; 1990. p. 81-107.

Bowmaker JK, Govardovskii VI, Shukolyukov SA, Zueva JLV, Hunt DM, Sideleva VG, Smirnova OG. Visual pigments and the photic environment: the cottoid fish of Lake Baikal. Vision Res. 1993;34(5):591-605.

Carleton KL, Kocher TD. Cone opsin genes of African cichlid fishes: tuning spectral sensitivity by differential gene expression. Mol Biol Evol. 2001 Aug;18(8):1540-50.

Caves EM, Brandley NC, Johnsen S. Visual Acuity and the Evolution of Signals. Trends Ecol Evol. 2018a May;33(5):358-72.

Caves EM, Green PA, Johnsen S. Mutual visual signalling between the cleaner shrimp Ancylomenes pedersoni and its client fish. Proc $\mathrm{R}$ Soc Lond, Ser B: Biol Sci. 2018b;285(1881):20180800.

Caves EM, Johnsen S. AcuityView: an r package for portraying the effects of visual acuity on scenes observed by an animal. Methods Ecol Evol. 2018;9(3):793-7.

Caves EM, Sutton TT, Johnsen S. Visual acuity in ray-finned fishes correlates with eye size and habitat. J Exp Biol. 2017 May;220(Pt 9):158696.

Champ CM, Vorobyev M, Marshall NJ. Colour thresholds in a coral reef fish. R Soc Open Sci. 2016 Sep;3(9):160399.

Champ C, Wallis G, Vorobyev M, Siebeck U, Marshall J. Visual acuity in a species of coral reef fish: Rhinecanthus aculeatus. Brain Behav Evol. 2014;83(1):31-42.

Cheney KL, Newport C, McClure EC, Marshall NJ. Colour vision and response bias in a coral reef fish. J Exp Biol. 2013 Aug;216(Pt 15):2967-73.

Cohn BA, Collin SP, Wainwright PC, Schmitz L. Retinal topography maps in R: new tools for the analysis and visualization of spatial retinal data. J Vis. 2015;15(9):19-19.

Collin SP, Marshall NJ, Fritsches KA, Partridge JC, Pettigrew JD, Marshall NJ. Colour vision in billfish. Philos Trans R Soc Lond, Ser B: Biol Sci. 2000;355(1401):1253-6.

Collin SP, Pettigrew JD. Retinal topography in reef teleosts. II. Some species with prominent horizontal streaks and high-density areae. Brain Behav Evol. 1988;31(5):283-95.

Collin SP, Pettigrew JD. Quantitative comparison of the limits on visual spatial resolution set by the ganglion cell layer in twelve species of reef teleosts. Brain Behav Evol. 1989;34(3):18492.

Dalrymple RL, Hui FK, Flores-Moreno H, Kemp DJ, Moles AT. Roses are red, violets are blue - so how much replication should you do? An assessment of variation in the colour of flowers and birds. Biol J Linn Soc Lond. 2015;114(1):69-81.

Dartnall HJ, Bowmaker JK, Mollon JD. Human visual pigments: microspectrophotometric results from the eyes of seven persons. Proc R Soc Lond, Ser B: Biol Sci. 1983;220(1218):11530.

Douglas RH, McGuigan CM. The spectral transmission of freshwater teleost ocular media an interspecific comparison and a guide to potential ultraviolet sensitivity. Vision Res. 1989;29(7):871-9.

Douglas RH, Partridge JC, Marshall NJ. The eyes of deep-sea fish. I: lens pigmentation, tapeta and visual pigments. Prog Retin Eye Res. 1998 Oct;17(4):597-636.

Dyer AG, Garcia JE, Shrestha M, Lunau K. Seeing in colour: a hundred years of studies on bee vision since the work of the Nobel laureate Karl von Frisch. Proc R Soc Vic. 2015;127(1):66-72.

Endler JA. On the measurement and classification of colour in studies of animal colour patterns. Biol J Linn Soc Lond. 1990;41(4):315-52.

Erisman BE, Allen LG. Color Patterns and Associated Behaviors in the Kelp Bass, Paralabrax clathratus (Teleostei: Serranidae). Bull South Calif Acad Sci. 2005;104(2):45-62, 18.

Escobar-Camacho D, Marshall J, Carleton KL. Behavioral color vision in a cichlid fish: $\mathrm{Me}$ triaclima benetos. J Exp Biol. 2017; 220(16):2887-99.

Fitze PS, Cote J, San-Jose LM, Meylan S, Isaksson C, Andersson S, et al. Carotenoid-based colours reflect the stress response in the common lizard. PLoS One. 2009;4(4):e5111.

Fritsches KA, Marshall NJ, Warrant EJ. Retinal specializations in the blue marlin: eyes designed for sensitivity to low light levels. Mar Freshw Res. 2003;54(4):333-41.

Govardovskii VI, Fyhrquist N, Reuter T, Kuzmin DG, Donner K. In search of the visual pigment template. Vis Neurosci. 2000 JulAug;17(4):509-28.

Govardovskiii VI, Zueva LV. Photoreceptors and visual pigments in fish from the black-sea. J Evol Biochem Physiol. 1988;24(4):436-40.

Grether GF, Hudon J, Endler JA. Carotenoid scarcity, synthetic pteridine pigments and the evolution of sexual coloration in guppies (Poecilia reticulata). Proc R Soc Lond, Ser B: Biol Sci. 2001;268(1473):1245-53.

Hager MC, Helfman GS. Safety in numbers: shoal size choice by minnows under predatory threat. Behav Ecol Sociobiol. 1991;29(4):2716.

Hart NS. Vision in the peafowl (Aves: Pavo cristatus). J Exp Biol. 2002 Dec;205(Pt 24):392535.

Hart NS. Microspectrophotometry of visual pigments and oil droplets in a marine bird, the wedge-tailed shearwater Puffinus pacificus: topographic variations in photoreceptor spectral characteristics. J Exp Biol. 2004 Mar;207(Pt 7):1229-40.

Hart NS, Lisney TJ, Marshall NJ, Collin SP. Multiple cone visual pigments and the potential for trichromatic colour vision in two species of elasmobranch. J Exp Biol. 2004 Dec;207(Pt 26):4587-94.

Hawryshyn CW, Haimberger TJ, Deutschlander ME. Microspectrophotometric measurements of vertebrate photoreceptors using CCD-based detection technology. J Exp Biol. 2001 Jul;204(Pt 14):2431-8. 
Hofmann CM, Carleton KL. Gene duplication and differential gene expression play an important role in the diversification of visual pigments in fish. Integr Comp Biol. 2009 Dec;49(6):630-43.

Hunter JR. Color Changes of Pelagic Prejuvenile Goatfish, Pseudupeneus grandisquamis, after Confinement in a Shipboard Aquarium. Copeia. 1967;1967(4):850-2.

Kelber A. Colour in the eye of the beholder: receptor sensitivities and neural circuits underlying colour opponency and colour perception. Curr Opin Neurobiol. 2016 Dec;41:106-12.

Kelber A, Vorobyev M, Osorio D. Animal colour vision - behavioural tests and physiological concepts. Biol Rev Camb Philos Soc. 2003 Feb;78(1):81-118.

Levine JS, MacNichol E Jr. Microspectrophotometry of primate photoreceptors: art, artifact, and analysis. In: Fein A, Levine JS, editors. The Visual System. New York: Liss; 1985. p. 73-87.

Lisney TJ, Collin SP. Retinal ganglion cell distribution and spatial resolving power in elasmobranchs. Brain Behav Evol. 2008;72(1):59-77.

Litherland L, Collin SP. Comparative visual function in elasmobranchs: spatial arrangement and ecological correlates of photoreceptor and ganglion cell distributions. Vis Neurosci. 2008 Jul-Aug;25(4):549-61.

Loew ER, Lythgoe JN. The ecology of cone pigments in teleost fishes. Vision Res. 1978;18(6):715-22.

Loew ER, McFarland WN, Margulies D. Developmental Changes in the Visual Pigments of the Yellowfin Tuna, Thunnus Albacares. Mar Freshwat Behav Physiol. 2002;35(4):235-46.

Losey GS, McFarland WN, Loew ER, Zamzow JP, Nelson PA, Marshall JN. Visual Biology of Hawaiian Coral Reef Fishes. I. Ocular Transmission and Visual Pigments. Copeia. 2003;2003(3):433-54.

Lukoschek V, McCormick M. A review of multispecies foraging associations in fishes and their ecological significance. Proceeding 9th International Coral Reef Symposium: Ministry of Environment, Indonesian Institute of Sciences and International Society for Reef Studies; 2002. p. 467-74.

Lythgoe JN. The Ecology of Vision. Oxford: Clarendon Press; 1979.

Lythgoe JN, Partridge JC. Visual pigments and the acquisition of visual information. J Exp Biol. 1989 Sep;146(1):1-20.

Lythgoe JN, Partridge JC. The modelling of optimal visual pigments of dichromatic teleosts in green coastal waters. Vision Res. 1991;31(3):361-71.

MacNichol EF. A unifying presentation of photopigment spectra. Vision Res. 1986;26(9):1543-56.

Maia R, Gruson H, Endler JA, White TE. pavo 2: new tools for the spectral and spatial analysis of colour in R. Methods Ecol Evol. 2019;10(7):1097-107.
Maia R, White TE. Comparing colors using visual models. Behav Ecol. 2018;29(3):649-59.

Marshall JN. Communication and camouflage with the same bright colours in reef fishes. Philos Trans R Soc Lond, Ser B: Biol Sci. 2000:355(1401):1243-48

Marshall J. Vision and lack of vision in the ocean. Curr Biol. 2017 Jun;27(11):R494-502.

Marshall J, Carleton KL, Cronin T. Colour vision in marine organisms. Curr Opin Neurobiol. 2015 Oct;34:86-94.

Marshall NJ, Vorobyev M. The design of color signals and color vision in fishes. In: Collin SP, Marshall JN, editors. Sensory processing in aquatic environments. New York: Springer-Verlag; 2003. p. 194-222.

Marshall J, Vorobiev M, Siebeck U. What does a reef fish see when sees a reef fish? Eating Nemo. In: Kapoor BG, Ladich F, Collin SP, editors. Communication in fishes. Enfield: Science Publisher; 2006.

Mäthger LM, Land MF, Siebeck UE, Marshall NJ. Rapid colour changes in multilayer reflecting stripes in the paradise whiptail, Pentapodus paradiseus. J Exp Biol. 2003 Oct;206(Pt 20):3607-13.

Michiels NK, Anthes N, Hart NS, Herler J, Meixner AJ, Schleifenbaum F, et al. Red fluorescence in reef fish: a novel signalling mechanism? BMC Ecol. 2008 Sep;8(1):16.

Miller EF, Allen LG. Observations on the Mating Behavior of Captive Spotted Sand Bass (Paralabrax maculatofasciatus). Bull South Calif Acad Sci. 2006 105(1):17-29, 13

Mosk V, Thomas N, Hart NS, Partridge JC, Beazley LD, Shand J. Spectral sensitivities of the seahorses Hippocampus subelongatus and Hippocampus barbouri and the pipefish Stigmatopora argus. Vis Neurosci. 2007 MayJun;24(3):345-54.

Munz FW, McFarland WN. Part I. Presumptive cone pigments extracted from tropical marine fishes. Vision Res. 1975;15(10):1045-62.

Musilova Z, Cortesi F, Matschiner M, Davies WI, Patel JS, Stieb SM, et al. Vision using multiple distinct rod opsins in deep-sea fishes. Science. 2019 May;364(6440):588-92.

Neumeyer C. Wavelength discrimination in the goldfish. J Comp Physiol A Neuroethol Sens Neural Behav Physiol. 1986;158(2):203-13.

Nilsson Sköld H, Aspengren S, Wallin M. Rapid color change in fish and amphibians - function, regulation, and emerging applications. Pigment Cell Melanoma Res. 2013 Jan;26(1):29-38.

Osorio D, Vorobyev M. Photoreceptor sectral sensitivities in terrestrial animals: adaptations for luminance and colour vision. Proc R Soc Lond, Ser B: Biol Sci. 2005;272(1574):174552.

Parker AN, Fritsches KA, Newport C, Wallis G, Siebeck UE. Comparison of functional and anatomical estimations of visual acuity in two species of coral reef fish. J Exp Biol. 2017 Jul;220(Pt 13):2387-96.
Partridge JC, Speare P, Shand J, Muntz WR, Williams DM. Microspectrophotometric determinations of rod visual pigments in some adult and larval Australian amphibians. Vis Neurosci. 1992 Aug;9(2):137-42.

Phillips GA, Carleton KL, Marshall NJ. Multiple Genetic Mechanisms Contribute to Visual Sensitivity Variation in the Labridae. Mol Biol Evol. 2016 Jan;33(1):201-15.

Pignatelli V, Champ C, Marshall J, Vorobyev M. Double cones are used for colour discrimination in the reef fish, Rhinecanthus aculeatus. Biol Lett. 2010 Aug;6(4):537-9.

Pryke SR, Griffith SC. Red dominates black: agonistic signalling among head morphs in the colour polymorphic Gouldian finch. Proc R Soc Lond, Ser B: Biol Sci. 2006;273(1589):94957.

R Core Team. R: a language and environment for statistical computing. 2020. Available from: https://www.R-project.org/.

Rodgers GM, Gladman NW, Corless HF, Morrell LJ. Costs of colour change in fish: food intake and behavioural decisions. J Exp Biol. 2013 Jul;216(Pt 14):2760-7.

Ross PM, Thrush SF, Montgomery JC, Walker JW, Parsons DM. Habitat complexity and predation risk determine juvenile snapper (Pagrus auratus) and goatfish (Upeneichthys lineatus) behaviour and distribution. Mar Freshw Res. 2007;58(12):1144-51.

Savelli I, Novales Flamarique I, Iwanicki T, Taylor JS. Parallel opsin switches in multiple cone types of the starry flounder retina: tuning visual pigment composition for a demersal life style. Sci Rep. 2018 Mar;8(1):4763.

Sazima C, Krajewski JP, Bonaldo RM, Guimarães PR Jr. The goatfish Pseudupeneus maculatus and its follower fishes at an oceanic island in the tropical west Atlantic. J Fish Biol. 2006;69(3):883-91.

Schneider CA, Rasband WS, Eliceiri KW. NIH Image to Image): 25 years of image analysis. Nat Methods. 2012 Jul;9(7):671-5.

Schweikert LE, Fitak RR, Caves EM, Sutton TT, Johnsen S. Spectral sensitivity in ray-finned fishes: diversity, ecology and shared descent. J Exp Biol. 2018 Nov;221(Pt 23):jeb189761.

Seward AJ. Visual Ecology of Australian Flathead. Biological Sciences. Sydney: Macquarie University; 2018

Shand J. Changes in the spectral absorption of cone visual pigments during the settlement of the goatfish Upeneus tragula: the loss of red sensitivity as a benthic existence begins. J Comp Physiol. 1993;173(1):115-21.

Shawkey MD, D'Alba L. Interactions between colour-producing mechanisms and their effects on the integumentary colour palette. Philos Trans R Soc Lond. Ser B: Biol Sci. 2017;1724:372.

Sibeaux A, Cole GL, Endler JA. Success of the receptor noise model in predicting colour discrimination in guppies depends upon the colours tested. Vision Res. 2019 Jun;159:86-95. 
Siebeck UE. Communication in coral reef fish: the role of ultraviolet colour patterns in damselfish territorial behaviour. Anim Behav. 2004;68(2):273-82.

Siebeck UE, Marshall NJ. Ocular media transmission of coral reef fish - can coral reef fish see ultraviolet light? Vision Res. 2001 Jan;41(2):133-49.

Siebeck UE, Wallis GM, Litherland L. Colour vision in coral reef fish. J Exp Biol. 2008 Feb;211(Pt 3):354-60.

Siebeck U, Wallis G, Vorobyev M. Colour discrimination in coral reef fish. 32nd European Conference on Visual Perception. Regensburg: Sage Publications; 2009. p. 39.

Sterratt DC, Lyngholm D, Willshaw DJ, Thompson ID. Standard anatomical and visual space for the mouse retina: computational reconstruction and transformation of flattened retinae with the Retistruct package. PLoS Comput Biol. 2013;9(2):e1002921.

Stuart-Fox D, Moussalli A. Selection for social signalling drives the evolution of chameleon colour change. PLoS Biol. 2008 Jan;6(1):e25.

Svensson W, Wong BBM. Carotenoid-based signals in behavioural ecology: a review. Behaviour. 2011;148(2):131-89.
Toyama M, Hironaka M, Yamahama Y, Horiguchi $\mathrm{H}$, Tsukada O, Uto N, et al. Presence of rhodopsin and porphyropsin in the eyes of 164 fishes, representing marine, diadromous, coastal and freshwater species - a qualitative and comparative study. Photochem Photobiol. 2008 Jul-Aug;84(4): 996-1002.

Uiblein F. Goatfishes (Mullidae) as indicators in tropical and temperate coastal habitat monitoring and management. Mar Biol Res. 2007;3(5):275-88.

Uiblein F. Taxonomic review of Western Indian Ocean goatfishes of the genus Mulloidichthys (Family Mullidae), with description of a new species and remarks on colour and body form variation in Indo-West Pacific species. Smithiana Bull. 2011;13:51-73.

Ullmann JF, Moore BA, Temple SE, FernándezJuricic E, Collin SP. The retinal wholemount technique: a window to understanding the brain and behaviour. Brain Behav Evol. 2012;79(1):26-44.

van den Berg CP, Hollenkamp M, Mitchell LJ, Watson EJ, Green NF, Marshall NJ, et al. More than noise: context-dependent luminance contrast discrimination in a coral reef fish (Rhinecanthus aculeatus). J Exp Biol. 2020 Nov;223(Pt 21):jeb232090.
Van-Eyk SM, Siebeck UE, Champ CM, Marshall J, Hart NS. Behavioural evidence for colour vision in an elasmobranch. J Exp Biol. 2011 Dec;214(Pt 24):4186-92.

Von Frisch K. Der Farbensinn und Formensinn der Biene. Zool Jahrb, Abt Allg Zool Physiol Tiere. 1914;37(1):1-187.

Vorobyev M, Osorio D. Receptor noise as a determinant of colour thresholds. Proc R Soc Lond, Ser B: Biol Sci. 1998;265(1394):351-8.

Vorobyev M, Osorio D, Bennett ATD, Marshall NJ, Cuthill IC. Tetrachromacy, oil droplets and bird plumage colours. J Comp Physiol A. 1998;183(5):621-33.

Warrant EJ. Seeing better at night: lifestyle, eye design and the optimum strategy of spatial and temporal summation. Vision Res. 1999 May;39(9):1611-30.

Warrant EJ, Locket NA. Vision in the deep sea. Biol Rev Camb Philos Soc. 2004 Aug;79(3):671-712.

Wedekind C, Meyer P, Frischknecht M, Niggli UA, Pfander H. Different Carotenoids and Potential Information Content of Red Coloration of Male Three-Spined Stickleback. J Chem Ecol. 1998;24(5):787-801.

White TE. Structural colours reflect individual quality: a meta-analysis. Biol Lett. 2020 Apr;16(4):20200001. 